\title{
Functional Differentiation of Adult Neural Circuits from a Single Embryonic Network
}

\author{
Béatrice Casasnovas and Pierre Meyrand \\ Laboratoire de Neurobiologie et Physiologie Comparées, Université Bordeaux I et CNRS, Arcachon, France 33120
}

\begin{abstract}
The stomatogastric nervous system (STNS) of adult lobsters and crabs generates a number of different rhythmic motor patterns which control different regional movements of the foregut. Since these output patterns are generated by discrete neural networks that, in the adult, are well characterized in terms of synaptic and cellular properties, this system constitutes an ideal model for exploring the mechanisms underlying the ontogeny of neural network organization. The foregut and its rhythmic motor patterns were studied in in vitro STNS nerve-muscle preparations of the embryo and different larval stages of the lobster Homarus gammarus. The development of Homarus comprises a long embryonic stage in ovo followed by three pelagic larval stages prior to the onset of benthic life. During these stages the foregut itself develops slowly from a simple ectodermal invagination that occurs in the embryo. During successive larval stages it progressively acquires all the specialized structures and shape of the adult foregut. In contrast, the STNS is morphologically recognizable at early embryonic stages. In all recorded stages the STNS spontaneously expresses rhythmic motor activity. During development, this activity is progressively restructured, beginning with a single rhythmic motor pattern in the embryo where all the stomodeal muscles are strongly coordinated. In subsequent stages, however, this single pattern is progressively subdivided to give rise eventually to the three discrete rhythmic motor patterns characteristic of the adult STNS. Our data suggest that rather than a dismantling of redundant embryonic and larval neural networks, the different adult networks emerge as a progressive partitioning of discrete circuits from a single embryonic network.

[Key words: Crustacea, stomatogastric nervous system, neural networks, development, embryonic central pattern generator, motor rhythm ontogeny]
\end{abstract}

Determining the developmental mechanisms that allow the elaboration and maturation of complex adult behavior is one of the fundamental issues in the neurosciences (Fentress, 1992). Among the multitude of tasks performed by an animal, the easiest to observe and study are rhythmic motor behaviors that are

\footnotetext{
Received Dec. 15, 1994; revised Mar. 30, 1995; accepted Mar. 31, 1995.

We express our gratitude to Drs. Golowasch, Nusbaum, and Simmers for their extremely useful criticisms of the manuscript and their communicative enthusiasm. We thank Dr. Moulins for his support. This work was supported by anl HFSP grant.

Correspondence should be addressed to Pierre Meyrand, Laboratoire de Neurobiologie et Physiologie Comparées, Université Bordeaux I et CNRS, Place du Dr. Pcyncau, 33120 Arcachon, France.

Copyright $(\mathcal{C} 1995$ Society for Neuroscience $0270-6474 / 95 / 155703-16 \$ 05.00 / 0$
}

generated by neural networks called central pattern generators, or CPGs (Grillner, 1985; Harris-Warrick and Marder, 1991; Pearson, 1993). From studies of invertebrates (Getting, 1989) and vertebrates (Grillner et al., 1990; Pearson, 1993), it is now clear that the organizational principles that underlie CPGs of the adult nervous system are similar.

However, far less information is available on the ontogeny of these neural networks. Whereas some models support the idea that these networks are assembled and later discarded as a function of stage-specific needs during development (Truman, 1992), other models suggest that early in development an immature precursor network is built which progressively acquires the adult characteristics (Cohen et al., 1990; Sillar et al., 1992a). For instance, in humans, behavioral studies of the ontogeny of locomotion show that locomotor-like movement occurs from the first weeks after conception (De Vries et al., 1982). However, even while locomotor movements can be elicited immediately after birth during a narrow time window (Peiper, 1963) it takes a year before children can walk independently. From different studies, it has emerged that the same general sequential changes occur during the ontogeny of rhythmic motor behaviors in many vertebrates, including rats (Bekoff and Lau, 1980; Cazalets et al., 1990), birds (Watson and Bekoff, 1990), and amphibians (Stehouwer and Farel, 1985).

While these studies provide some general clues about the development of rhythmic motor behaviors, they are limited by the fact that the neural network organization underlying such activities in the mature nervous system remains poorly described at the cellular level. In contrast, studies of rhythmic motor activities in invertebrates have provided considerable insight into neural network organization. Such knowledge can be the starting point for understanding the general principles which govern the development of a given CPG, and hence of a given behavior. Among these invertebrate models, the lobster stomatogastric nervous system (STNS) is particularly attractive since the neural networks controlling the motions of the lobster foregut are nuw very well known in terms of cellular and synaptic properties in the adult (Harris-Warrick et al., 1992a). Until now, however, nothing is known about the organizational rules that govern these networks and their constituent neurons during the course of development.

In the present study we have examined the development of the foregut and STNS in lobster Homarus gammarus. We find that the stomodeum (the rudimentary foregut) and the STNS are morphologically present early in the embryo (as early as $12 \%$ of development, E12). Moreover, the stomatogastric ganglion (STG), which contains two well-characterized networks in the adult, can be identified unambiguously at E12. However, while 
the adult STNS generates four discrete motor patterns, the STNS of the embryo spontaneously displays a single rhythmic motor pattern which controls coordinated movements of the entire stomodeum. Our data suggest that, rather than discarding the single embryonic network to create four new adult ones or a progressive maturation of four discrete immature neural networks, the same neural network is progressively differentiated into multiple neural networks during development.

Some of this work was published previously in abstract form (Casasnovas et al., 1991).

\section{Materials and Methods}

All experiments were performed on embryos $(n=137)$, larvae $(n=$ $24)$ or adults $(n=12)$ of the European lobster Homarus gammarus.

Embryos were collected from gravid females obtained from a local fishery supply and kept in large tanks of circulating and acratcd scawater. The embryonic phase requires $6-9$ months under laboratory conditions. By holding gravid females with embryos at different developmental stages at constant temperature $\left(15^{\circ} \mathrm{C}\right)$, we were able to maintain developmental rate constant and therefore had a continuous supply of embryos throughout the year. All other adults, weighing $300-400 \mathrm{gm}$, were maintained in the same laboratory conditions.

Larval raising was also carried out in the laboratory. After hatching, the larvae were transferred to a culture system consisting of a grid of small rearing troughs $\left(150 \mathrm{~cm}^{3}\right)$ flushed with recirculating aerated seawater at $15^{\circ} \mathrm{C}$. Each rearing trough contained only one larva. The larvae were fed twice daily with frozen Artemia and the entire culture system was cleaned daily.

\section{Developmental staging}

To determine the embryonic stage of development, we adopted a staging procedure established by Perkins (1972) and modified by Helluy and Beltz $(1990,1991)$ for Homarus americanus. This staging indicator, the eye index $(E I)$, is based on the progression of the size of the pigmentation of the lateral eye (Le; see Fig. 2) during the course of embryonic development. The eye index is defined as the average length and width of the brown pigmentation of the lateral eye. Measurements were made with an ocular micrometer on a binocular microscope. The eye index is first measurable at $70 \mu \mathrm{m}$ and increases to $580 \mu \mathrm{m}$ at hatching. According to Helluy and Beltz (1991), each value of EI can be converted into a percentage of the embryonic development by dividing the measured EI at a given time by EI at hatching. Thus, hatching corresponds to $100 \%$ of the embryonic development (E100), E50 to halfway through embryogenesis and E0 to fertilization.

\section{Electrophysiology}

Electrophysiological experiments were performed on both embryos and larvae at different developmental stages, as well as adults. Different types of in vitro preparations were used.

Embryonic nervous system-muscle preparation. The egg membranes were removed and the embryo was separated from the yolk in physiological saline. The whole foregut was dissected from the embryo by removing limbs, antennae, and the abdomen. The foregut was then split open along the ventral midline, laid flat and fastened to a Sylgard-lined petri dish. Only the stomatogastric ganglion (STG) and the proximal ends of its afferent and efferent nerves were dissected free from the muscles. The STG was then mechanically desheathed, to provide access to the cell bodies, using two fine metallic needlepoints installed on micromanipulators. This technique prevents damage to the major parts of the vesophageal, gastric and pyloric muscles, despite the small size of the preparation (the entire embryo is approximately 1-2 $\mathrm{mm}$ in length). This preparation allowed us to record simultaneously the activity of muscle fibers from the different stomodeal regions and from the somata of motoneurons in the STG.

Larval nervous system-muscle preparation. Larvae were pinned dorsal side up, through the telson and the rostrum, then the anterior foregut was exposed by removing the cephalothoracic carapace. Subsequent dissection steps were as described above for the embryo.

Adult isolated stomatogastric nervous system (STNS) preparation. The adult preparation was dissected as described by Meyrand et al. (1994). It consists of the isolated STNS, which includes the stomatogastric ganglion (STG; containing 30 identified neurons), the oesopha- geal ganglion (OG; 12 neurons), the two commissural ganglia $(\mathrm{CoG}$; each with several hundred neurons) that lie on either side of the oesophagus, plus their interconnecting nerves including the single stomatogastric nerve (stn) which links the STG with the other three ganglia. The motor nerves that exit the $S T G$ toward the caudal region of the foregut were usually dissected to a point very close to the muscles they innervate, in order to obtain single units with extracellular recordings.

All types of preparation were superfused continuously with oxygenated physiological saline and maintained at $12-13^{\circ} \mathrm{C}$. The saline $\mathrm{com}-$ position was (in mM) $479.12 \mathrm{NaCl}, 12.74 \mathrm{KCl}, 13.2 \mathrm{CaCl}_{2}, 10 \mathrm{MgSO}_{4}$, $3.9 \mathrm{Na}_{2} \mathrm{SO}_{4}, 5$ HEPES, pH 7.45 (Sigma). Intracellular recordings were made from STG neuron somata and muscle fibers using thin wall glass microelectrodes $(20-40 \mathrm{M} \Omega$ ) filled with $0.6 \mathrm{M}$ potassium sulfate plus $20 \mathrm{mM} \mathrm{KCl}$. World Precision Instruments and Axoclamp 2A (Axon Instruments) amplifiers were used for intracellular recordings and current injection. Extracellular recordings were obtained with either suction electrodes applied to embryonic muscles or, for the adult recordings, with thin platinum wire electrodes placed against appropriate nerves and insulated with Vaseline. Data were displayed on a ES 1000 electrostatic recorder (GOULD) and simultaneously stored on a tape recorder (VHS, JVC).

\section{Histology}

The same procedure was performed for all stages of embryo and larva. Whole specimens were fixed for $5 \mathrm{hr}$ in Bouin's fixative which includes $250 \mathrm{ml}$ of saturated picric acid, $750 \mathrm{ml}$ of $37 \%$ formaldehyde, and 50 $\mathrm{ml}$ of concentrated acetic acid. Samples were then washed for $15 \mathrm{~min}$ in a TRIS- $\mathrm{NaCl}$ buffer $(0.9 \%$ sodium chloride at $\mathrm{pH} 7.6)$. The preparations were next dehydrated progressively in ethanol of increasing concentration from $30 \%$ to $100 \%, 10 \mathrm{~min}$ for each step, and cleared twice $90 \mathrm{~min}$ in supercedrol at room temperature. Finally, the entire specimen was embedded in Paraplast wax $\left(60-63^{\circ} \mathrm{C}\right.$ melting point) and serially sectioned in the sagittal plane $(6$ to $10 \mu \mathrm{m})$ so as to visualize the stomodeum and stomatogastric nervous system on the same section. The sections were routinely stained with cresyl violet $(1 \%)$ to mark nerve cells (Heym and Forssmann, 1981), mounted in Entellan, coverslipped, and then observed and photographed through a Leitz orthoplan microscope.

\section{Results}

The adult stomatogastric nervous system in vitro

In Homarus gammarus, as in other large crustaceans (spiny lobster and crab), the adult foregut consists of two main regions, a short oesophagus and a large stomach (Fig. 1A). This latter is divided in three discrete compartments, the anterior cardiac sac, the gastric mill system, and the posterior pyloric chamber. The cardiac sac region seems to be involved in the cyclic repositioning of food for processing by the gastric mill system. However, while the cardiac rhythm is spontaneously expressed in vitro in the spiny lobster STNS (Moulins and Vedel, 1977; Dickinson et al., 1993) it has never been observed in vitro in H. gammarus (Meyrand et al., 1994). The gastric mill system consists of two lateral teeth and a single medial tooth which together shred food inside the stomach, while the pyloric chamber serves as a filter that controls the movement of food particles toward the intestine.

The movements of each foregut region result from rhythmic contractions of striated muscles innervated by motoneurons of the STNS. When the STNS of the adult lobstcr is isolated in vitro, three different rhythmic motor patterns with distinctly different cycle frequencies are produced spontaneously and continuously as seen in Figure $1 B$ where two members each of the oesophageal, gastric and pyloric networks are monitored simultaneously. The pyloric rhythm, which is the fastest STNS rhythm with a period of $1-2 \mathrm{sec}$, is generated by a well-defined network of 12 STG neurons. The slowest thythm in the Homarus STNS in vitro is generated by the gastric network, which also consists of identified STG neurons and whose period is usually 10-20 sec. As for the pyloric network, the mechanisms underlying the 


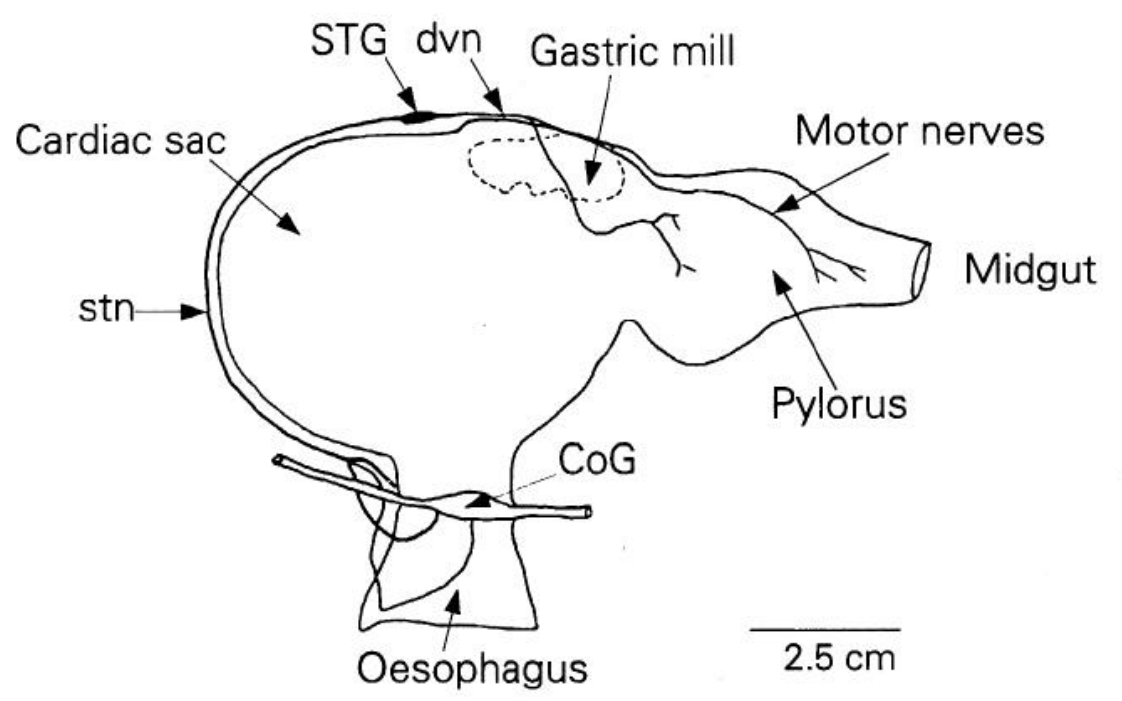

B
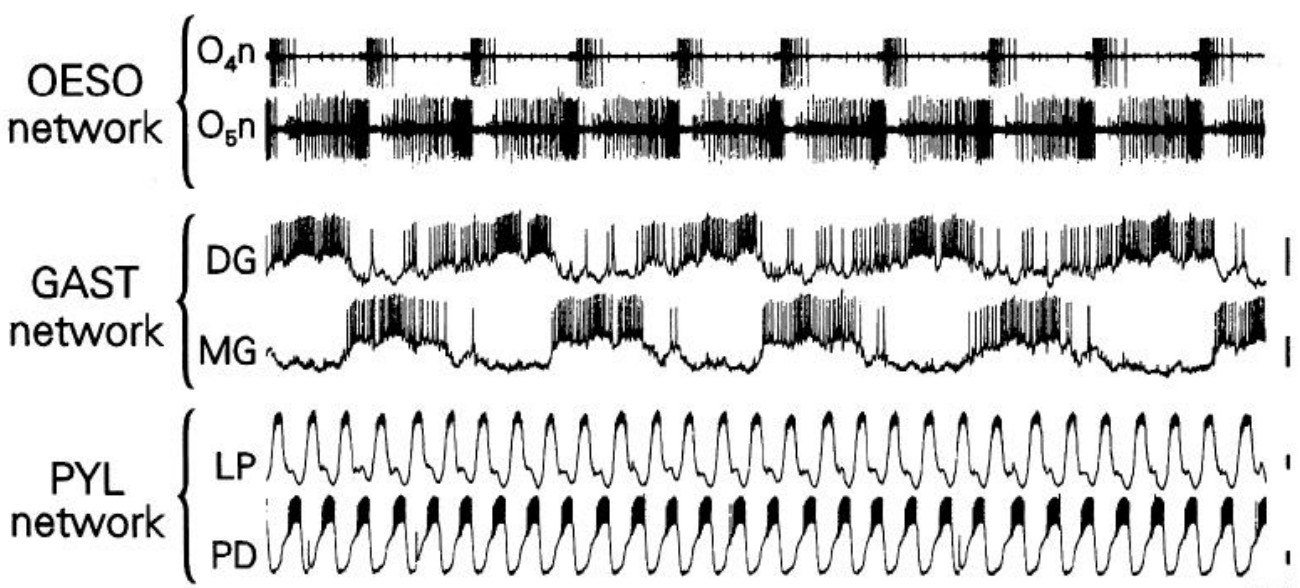

Figure 1. The stomatogastric nervous system (STNS) of the adult lobster (Homarus gammarus). A, Schematic left lateral view of the adult anterior foregut showing the three main functional regions (oesophagus, gastric mill, pylorus) and the STNs in situ. $B$, Distinct spontaneous rhythmic activity of the three corresponding networks in an adult STNS isolated in vitro. The oesophageal, gastric, and pyloric networks monitored simultaneously with an extracellular electrode from the constrictor oesophageal nerve $(O 4 n)$ and dilator oesophageal nerve $(O 5 n)$, and intracellularly from the dorsal gastric $(D G)$, the median gastric $(M G)$, lateral pyloric $(L P)$, and pyloric dilator $(P D)$ neurons. Abbreviations: $d v n$, dorsal ventricular nerve; $C o G$, commissural ganglion; Gast, gastric mill; Oeso, oesophagus; Pyl, pyloric neuron; STG, stomatogastric ganglion; $s t n$, stomatogastric nerve. Calibration: $10 \mathrm{mV}, 1$ sec. synaptic and cellular organization of the gastric network have been extensively studied (Harris-Warrick et al., 1992a). The oesophageal rhythm expresses an intermediate period (4-8 sec) generated by an ensemble of neurons distributed in the oesophageal and commissural ganglia.

\section{Ontogeny of the foregut}

The developmental stages of Homarus had been extensively described since the pioneering work of Herrick (1895) and Bumpus (1891), and more recently by Helluy and Beltz (1991) and Beltz et al. (1992). The principal features of the lobster Homarus gammarus development are summarized in Figure 2. Egg development lasts for 6-9 months after fertilization while three successive planktonic larval stages (LI, LII, LIII) follow hatching. This period lasts 1-3 months and ends with a metamorphosis leading to the adult-like larva called post-larva IV. In contrast to the slow and continuous embryonic development, larval development is a discontinuous process. Each larval stage is separated by a molt which is accompanied by discrete anatomical alterations. Larval stage I (LI) is characterized by the absence of abdominal appendages (pleopods) and by the trapezoidal shape of the hindmost segment of the abdomen or telson. The most important change that occurs in the second larval stage (LII) is the appearance of rudimentary swimmerets, on the underside of the abdomen. The following larval stage (LIII) is characterized by the acquisition of a pair of uropods supplied by the last abdominal segment, on both sides of the telson. The third molt, which is considered the metamorphosis, gives rise to a juvenile lobster or post-larva IV. Apart from its size, it looks like an adult lobster and is benthic.

Although the developmental periods of Homarus have been described (Bumpus, 1891; Herrick, 1895; Beltz et al., 1992), there are no reports on the development of the embryonic foregut or stomodeum of lobsters or other large crustaceans. Thus, using histological techniques (see Materials and Methods) we followed the morphological development of the stomodeum which can be detected very early in the embryo of Homarus as an invagination of the ectoderm between the brain and the ventral nerve cord. At E12 (Fig. 3A) the stomodeum looks like a tiny bag embedded between three different embryonic structures; anteriorly, the future brain $(\mathrm{Br})$; dorsally, the yolk (at this 


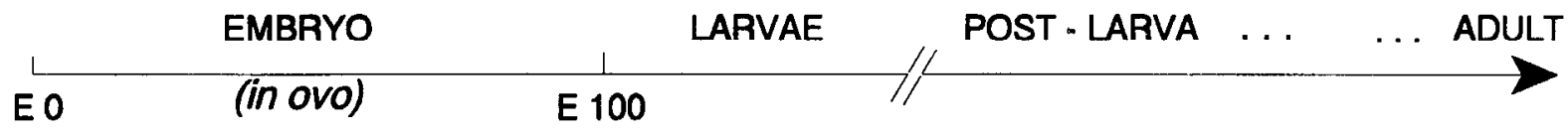

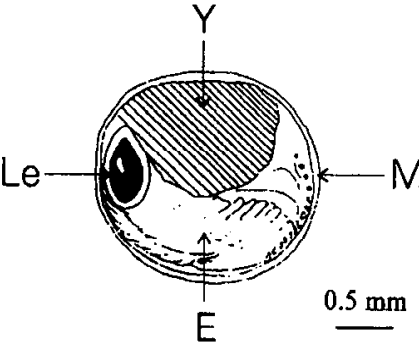

E 70

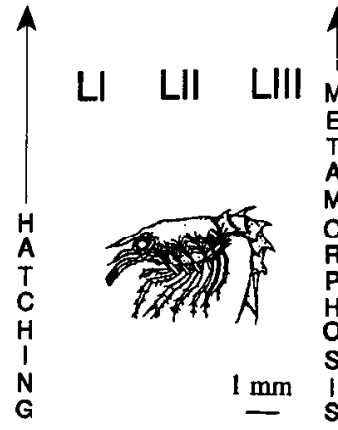

LI

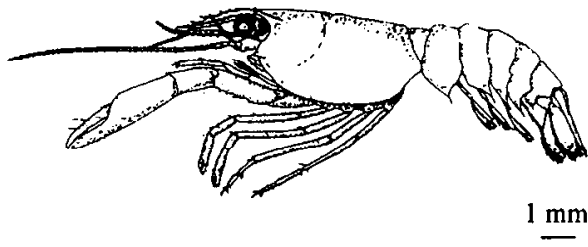

POST-LARVA IV

\section{(6-9 months) (7-12 months)}

(5-7 years)

Figure 2. Developmental timetable of the lobster H. gammarus. The development of Homarus gammarus occurs in three major phases: an embryonic phase, a larval period, and a postlarval phase. Animal from each phase is illustrated. In all the cases, dorsal is at the top and the head is to the left. Embryo is illustrated at $70 \%$ of development $(E 70)$ inside its egg membrane. The first larval stage $(L I)$ is illustrated in the middle. After metamorphosis, the post-larva IV (right) progressively acquires the adult characteristics. The times given in parentheses indicate when hatching, metamorphosis and adulthood occur after fertilization. $E$, Embryo; $E O$, fertilization; $E 100$, hatching; $L e$, lateral eye; $L I$, first larval stage; $L I I$, second larval stage; $L I I I$, third larval stage; $M$, egg membranes; $Y$, yolk.

stage the yolk occupies about $95 \%$ of the egg's volume); ventrally, the future ventral nerve cord (VNC).

Besides an increase in size, the stomodeum shows little dramatic morphological modification during the first half of the embryonic period. At E50 some parts of the embryo, such as the abdomen, are already well developed (see Fig. $3 B$, Abd.), but the stomodeum remains a closed bag. However, at this stage the distal part of this invagination hecomes thicker relative to the other parts of the stomodeum (Fig. $3 B,{ }^{*}$ ). During the subsequent developmental period (E60-70), this region will give rise to the future pyloric chamber.

During the second half of the embryonic period, particularly between E50 and E75, the stomodeum undergoes dramatic morphological changes involving the differentiation of the various regions into adult-like structures. Indeed, from E75 to prehatching, the morphology of the stomodeum remains stable except for an increase in size, and it is possible to recognize the different regions characteristic of the adult foregut (compare Figs. 1A, $3 C$ ). Just before hatching (as in Fig. 3C), the stomodeum consists of an oesophagus (OESO) connecting the mouth to a large cardiac sac $(\mathrm{Cs})$, which lies adjacent to the pyloric chamber (PYL). During this period, the wall of the stomodeum, which initially consists of a single coating of rectangular-shaped cells, is replaced progressively by a thin chitinous wall. Although at the end of embryonic life the stomodeum is similar to the adult foregut, two striking features still distinguish them. First, the embryonic stomodeum has no internal teeth of the gastric mill system (Fig. $3 C^{C}$ ). These teeth appear later, during the larval period. As for Homarus americanus (Factor, 1981), the rudimentary medial tooth appears at larval stage III, whereas the two lateral teeth appear at post-larva IV. Second, throughout the entire embryonic life the stomodeum is a "blind bag" and does not communicate with the midgut until hatching (see Fig. $3 A, B$ ). Even during the prehatching period, when the stomodeum is physically in contact with the midgut, there is still a fine membrane separating them (see Fig $3 C, * *$ ). This lack of communication with the embryonic midgut was confirmed by injecting a vital dye (fast green) into the stomodeum of prehatching embryos $(n=4)$. Several hours after injection the dye remained confined to the stomodeum. We also found a "cork-like" structure which acts as a plug inside the oesophagus.

In summary, the stomodeum develops from an invagination of the ectoderm. During the second half of the embryonic period, it becomes morphologically similar to the adult foregut, although the gastric mill apparatus is still absent. Although occluded at the time of hatching the stomodeum becomes functional soon after. During the course of the larval period, as described for Homarus americanus (Factor, 1981), the foregut pro-

Figure 3. Ontogeny of the stomodeum in the lobster embryo stained with cresyl violet. Parasagittal sections of embryos at different stages of development E12 $(A), \mathrm{E} 50(B)$, and perihatching E98 $(C)$. A, An early stage embryo $(E 12)$ indicating the position of the stomodeum $(S t)$ or future foregut, between the brain $(B r)$ anteriorly, the ventral nerve cord $(V N C)$ posteriorly, and the yolk dorsally, $B$, Overview of a dissected embryo at E50 showing that the stomodeum occupies the same place between the brain anteriorly, the ventral nerve cord posteriorly and the abdomen $(A b d)$ ventrally. The stomodeum (at E50) is still an undifferentiated ectodermal invagination with a thickening of the distal part of its wall (*) which will give rise to the future pyloric region. $C$, Just before hatching $(E 98)$, the different adult-like regions are recognizable: the oesophagus $(O e s o)$, the cardiac sac $(C s)$, and the pyloric filter $(P y l)$. The stomodeum remains closed until after hatching with a fine membrane $\left({ }^{* *}\right)$ that separates it from the midgut $(M g t)$. A, Antcrior; $A b d$, abdomen; $B r$, brain; $C s$, cardiac sac; $D$, dorsal; $M g t$, midgut; $P$, posterior; $P y l$, pyloric filter; $O E S O$, ocsophagus; $S t$, stomodeum; $V$, ventral; $V N C$, ventral nerve cord. Scale bars, $100 \mu \mathrm{m}$. 
A E12
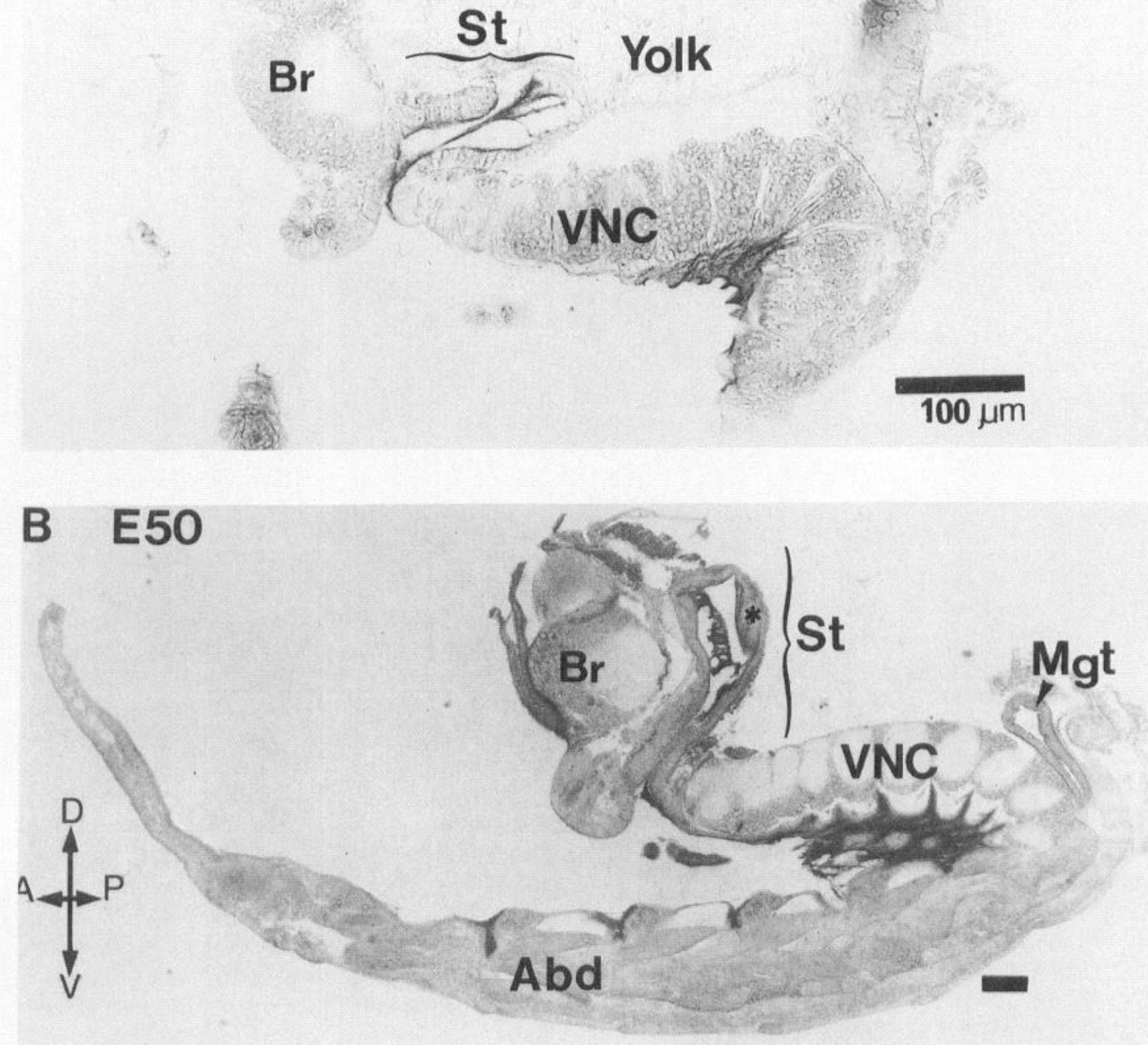

C $\quad$ E98

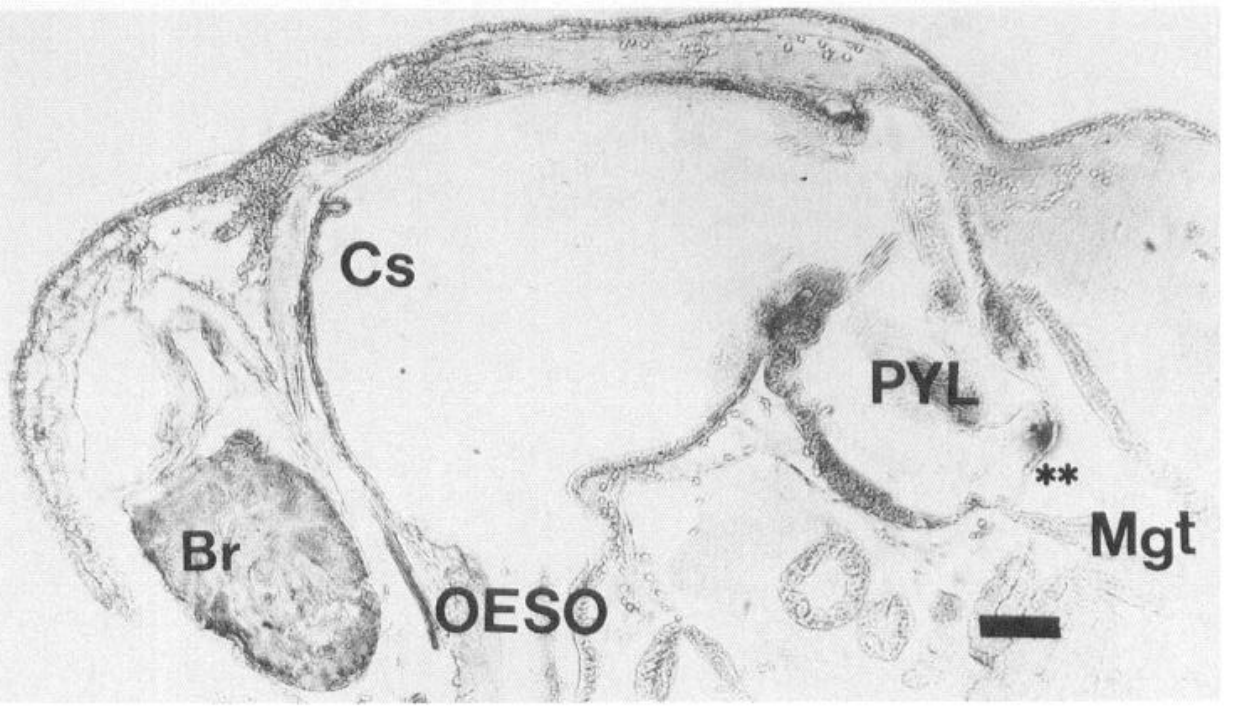


gressively acquires the teeth of the gastric mill system and becomes morphologically identical to the adult foregut.

\section{Ontogeny of the stomatogastric nervous system}

In contrast to the continual slow changes in morphology of the stomodeum during the embryonic period, the STNS seems to be morphologically established very early. Indeed, the STG can be visualized as early as E5 using specific markers, such as a neuron-specific antibody (V. Garzino, personal communication). With histochemical techniques, the STG is unambiguously recognizable starting at E12. At E20, while the stomodeum is still an undifferentiated invagination of the ectoderm, the STG is already well defined (Fig. 4A). At this stage the STG has a similar location and morphological structure as the adult STG. The STG lies in the anterior dorsal part of the stomodeum, in close contact with its internal wall, and remains at this location throughout all subsequent developmental stages. Moreover, the general morphology of the STG itself seems to remain stable during the course of development. For example, at all stages, the cell bodies of the STG neurons lie along the dorsal perimeter of the ganglion whereas the central part is occupied by their neuropilar projections (Fig. $4 A-C$ ).

The principal nerves of the STG are also clearly present as early as E20. A single nerve emerges caudally to the STG that corresponds to the main motor nerve (the dorsal ventricular nerve, dvn), whereas rostrally a single input nerve (the stomatogastric nerve, stn) links the SIG to the rest of the CNS (Fig. $4 A$ ). Again this basic morphological layout remains the same throughout embryogencsis (Fig. $4 B$ ) and into the adult (Fig. 4C). Thus, except for its length $(50 \mu \mathrm{m}$ at E20, $100 \mu \mathrm{m}$ at E50, 1 $\mathrm{mm}$ for the adult; see Fig. 4), the embryonic STG appears morphologically identical to that of the adult. Significantly, moreover, the number of neurons within the STG remains the same at all developmental stages. In adult spiny lobsters, the STG contains 25-30 neuron cell bodies (Maynard and Dando, 1974; King, 1976). We found a similar number of somata within the adult STG in $H$. gammarus $(27.8 \pm 1.8, n=5)$. Based on serial sections through the entire STG at different embryonic stages (see Materials and Methods), we found the following average numbers of neuronal somata: at E20, $24.7 \pm 2.2(n=4)$; at E30-40, $29.3 \pm 2.8(n=6)$; at E50-60, 28.1 $\pm 2.8(n=7)$; at E70, $31.0 \pm 3.5(n=5)$; at hatching, $29.1 \pm 1.3(n=7)$. Although the average of neurons from one stage to another seem different, it must be noted that the means at any given embryonic stage are not statistically different from the adult's at the 0.05 level using a $t$ test. Thus, these results indicate that at E20 the STG and its neuronal population is already essentially established, at least quantitatively, and its number remains roughly stable through all subsequent developmental stages.

Other components of the STNS (the OG, the two CoGs and the anterior nerves which interconnect these ganglia) appear at the same time as the STG. However, while the main nerves arc well defined in the embryonic STNS (see Fig. $4 B$ ), it is difficult to follow the paths of the motonerves toward their muscle targets. This is because the main STG motonerve (dvn) divides into two branches which seem to terminate in a loose bundle of fibers, like a "horse tail," from which it was impossible to follow their projections using light microscopy. We were therefore interested in determining whether the stomodeal muscles are actually innervated by STNS motoneurons at these stages of development and, more specifically, whether the STG motoneurons innervate the embryonic pyloric and gastric muscies.
Identification of the embryonic STG motoneurons according to their muscle targets

One striking feature of the embryonic preparation in vitro is that it displays sustained, spontaneous rhythmic movements of the stomodeum, an observation that suggests that embryonic muscles are indeed functional. To assess whether these movements are driven by motoneurons, we made simultaneous intracellular recordings from single muscle fibers and STG somata (Fig. 5). In Figure 5A, at E34, a stomodeal muscle fiber (Stm) shows rhythmic bursts of EJPs indicating neuronal activation. That this is the case is illustrated in Figure $5 B$ where a burst of spikes in an embryonic STG motoneuron (E98), here elicited by depolarizing current injection ( $1 \mathrm{nA}$ ), evoked a burst of excitatory junction potentials (EJP) in a target muscle fiber (Fig. 5B1). Each neuronal action potential was followed, with a constant latency, by an EJP indicating direct connection between these two elements (Fig. 5B2). From this type of experiment we conclude that the embryonic STG neurons do innervate the stomodeal muscles.

The unambiguous identification of the embryonic STG motoneurons was achieved according to the muscles that they innervate. The stomodeal muscles themselves are identified according to their specific insertions onto the stomatogastric ossicles. These bone-like structures are well differentiated very early in development and their fates can be unambiguously followed throughout development. In this way, we were also able to identify individual muscles and trace them during embryogenesis and therefore identify their motoneurons. For example, in Figure $6 A$, the intracellular activity of a pyloric muscle, the lateral pyloric constrictor muscle ( $\mathrm{LPm})$, was recorded along with its STG motoneuron (LP) at E98 (Fig. 6A). The embryonic LP neuron exhibited spontaneous rhythmic bursts of action potentials which in turn evoked a burst of EJPs and contraction in the LP muscle. As seen in Figure $6 B$, the same experimental procedure allowed us to identify the motoneuron that in the adult innervates the return-stroke muscle (DGm) of the gastric medial tooth. It must be noted that in all experiments tested we found time locked EJPs with intracellular spikes of STG motoneurons $(n-11)$. Moreover, using this procedure, we have identified motoneurons belonging to all major future pyloric classes (PY, pyloric; LP, lateral pyloric; PD, pyloric dilator motoneurons) as well as the future gastric motoneurons which innervate intrinsic muscles such as DG (dorsal gastric) and LG (lateral gastric). However, because the embryonic STNS including the STG are so small ( $100 \mu \mathrm{m}$ for the STG; see Fig. $4 B$ ), it is difficult to record simultaneously from several neurons as is done routinely in the much larger adult STNS. This small size also precluded successful placement of extracellular electrodes on the main motor nerves (which are never longer than $500 \mu \mathrm{m}$ ) and so we were not able to obtain simultaneous recordings of the complete motor output generated by the embryonic STNS. To overcome this problem we recorded simultaneously the motoneuron driven activity of pyloric, gastric, and oesophageal muscles in embryonic nerve-muscle preparations.

\section{Ontogeny of multiple networks from a single embryonic network}

As described previously, the stomodeum becomes functional only after hatching. However, we find that it expresses spontaneous rhythmic activity as early as the stomodeum can be morphologically identified and on the basis of the earliest intracel- 

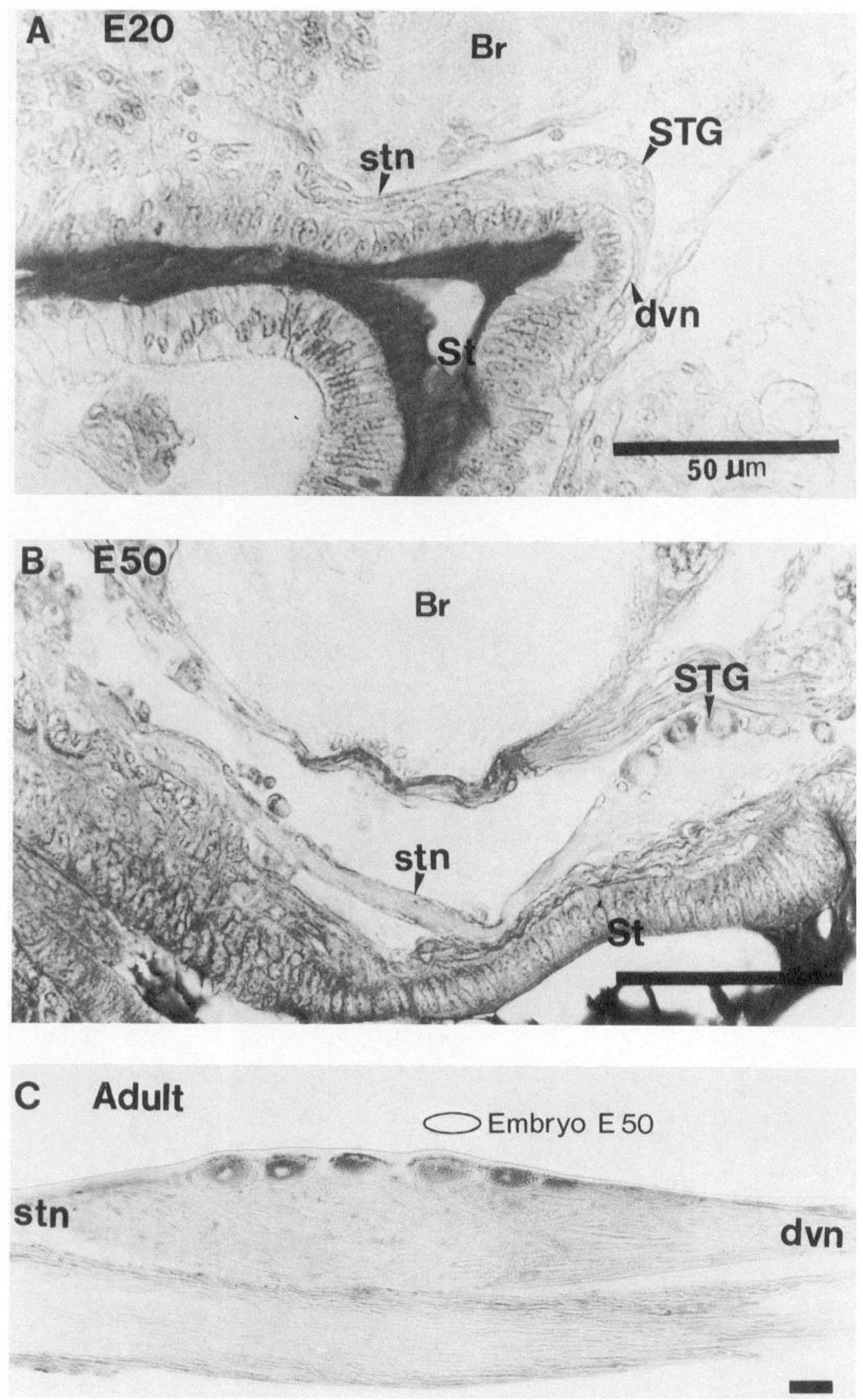

Figure 4. Histology of the stomatogastric ganglion (STG) at different developmental stages. Parasagittal sections from E20 $(A)$, E50 $(B)$, and the adult STG $(C)$ stained with cresyl violet. Beginning at E20, the STG is morphologically well formed, and the main nerves $(d v n$ and $s t n)$, are already established at E50. Excluding size differences, the embryonic STG strongly resembles the adult one. the ellipsoidal line drawing on the adult STG section represents a STG section for a E50 embryo using the same magnification. For abbreviations, see Figures 1 and 3 . Scale bars, $50 \mu \mathrm{m}$. 
A

E34

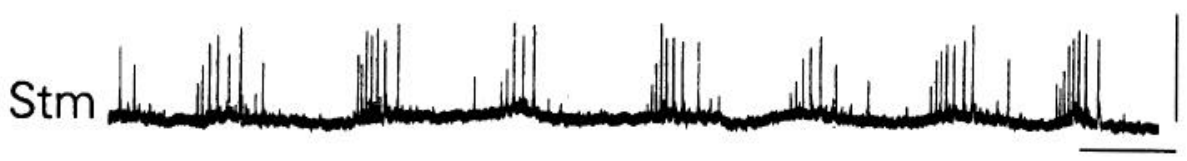

Figure 5. Identification of embryonic STG motoneurons. $A$, Intracellular recording from a stomodeal muscle fiber (Stm) at $34 \%$ of embryonic development (E34), during spontaneous rhythmic activity. $B$, Simultaneous intracellular recordings from the cell body $(M n)$ of a STG motoneuron and its corresponding target muscle $(m) . B l$, During a sustained depolarization (between arrowheads), the motoneuron (Mn) fired action potentials that evoked excitatory junction potentials $(E J P s)$ in the muscle fiber $(m) . B 2$, Four superimposed sweeps triggered by the motoneuron action potentials. Each EJP in the muscle fiber (upper trace) follows every action potential of Mn (bottom trace) with a constant latency. Calibration: $5 \mathrm{mV}, 1 \mathrm{sec}$.

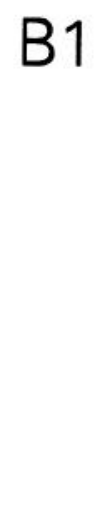

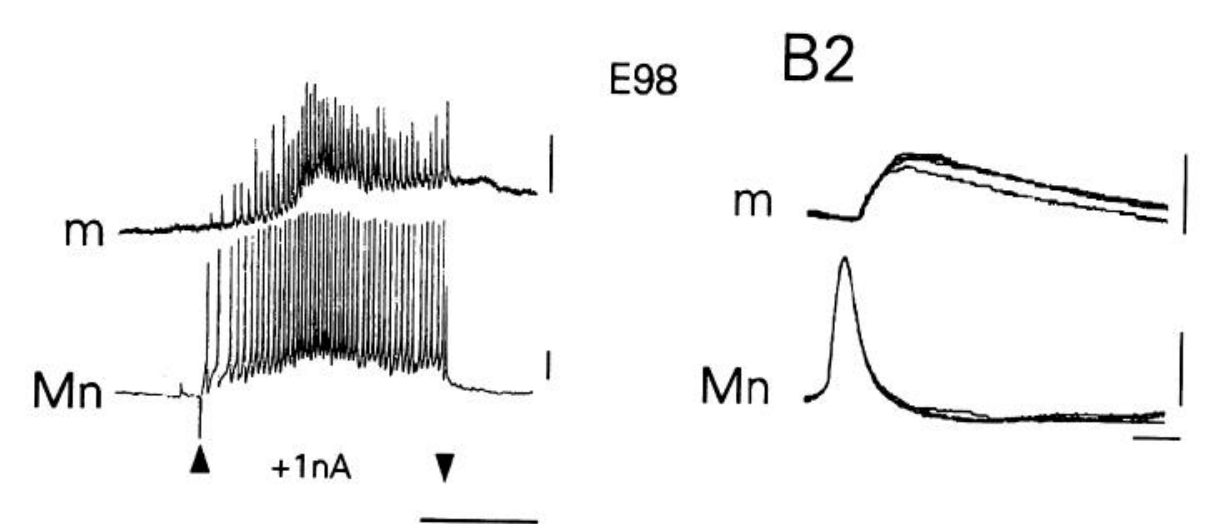

lular recordings from identified muscle fibers that could be obtained, which was at E34 (see Fig. 5A). A major finding of this study is that in the embryo, rhythmic activity of the future pyloric, gastric and oesophageal regions of the stomodeum are coordinated and that their rhythmic activities are linked together in a single motor pattern with a period typically of $0.75-3.5 \mathrm{sec}$
(Figs. 7A, 8). Using embryonic nervous system preparation with the STG undesheathed (see Materials and Methods), we found that this unique motor pattern was expressed in $70 \%$ of cases ( $n$ $=17)$. Most $(80 \%)$ of the remaining $30 \%$ of these preparations spontaneously expressed a single motor pattern where gastric bursts are missing every five to seven or sometimes more em-

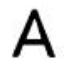

E98

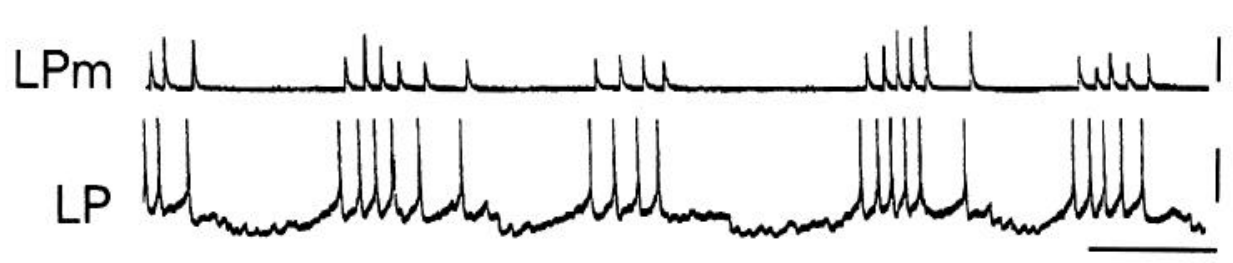

Figure 6. Identified, embryonic STG motoneurons. $A$, Identification of the lateral pyloric constrictor motoneuron $(L P)$. Simultaneous intracellular recordings in the LP soma and its muscle $(L P m)$. The action potentials in each burst of the LP neuron are followed one for one by EJPs in the LP muscle $(L P m) . B$, Identification of the dorsal gastric motoneuron $(D G)$. Simultaneous intracellular recordings in the DG soma and the muscle innervated by it $(D G m)$. Each DG action potential is followed by an EJP in the DG muscle $(D G m)$. Calibration: $5 \mathrm{mV}, 1 \mathrm{sec}$.

$B$

E80

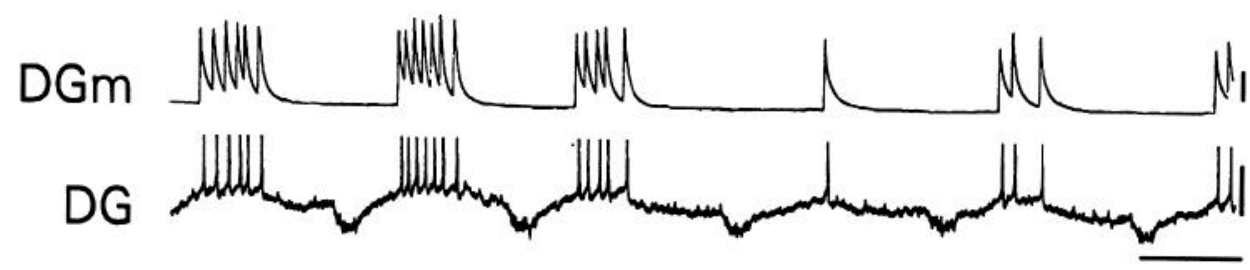


A

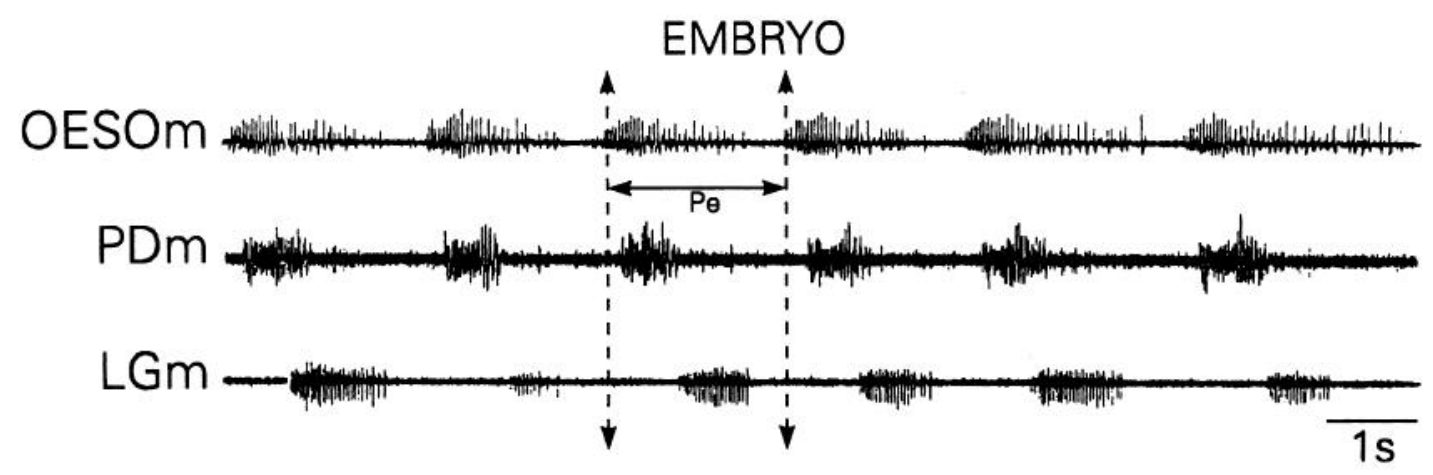

B

\section{ADULT}
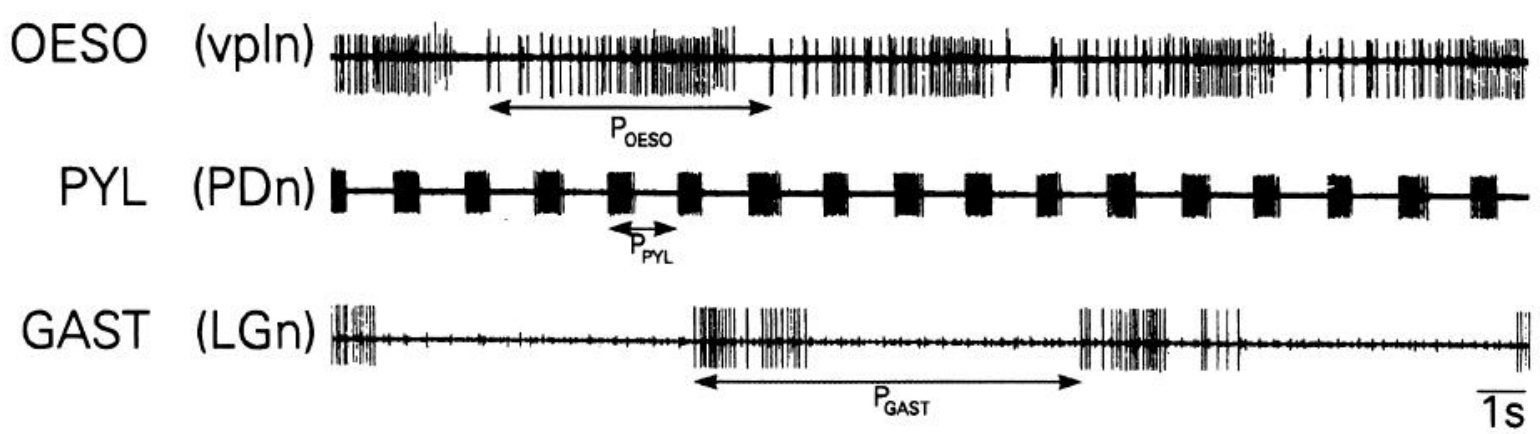

Figure 7. Comparison of the spontaneous rhythmic motor outputs of an embryonic $(A)$ and adult $(B)$ STNS. $A$, A single embryonic motor pattern monitored by simultaneous extracellular recordings from oesophageal $(O E S O m)$, pyloric dilator $(P D m)$, and lateral gastric $(L G m)$ stomodeal muscle fibers. Each embryonic muscle expresses rhythmic activity at the same period $\left(P_{\mathrm{e}}\right)$. $B$, Distinctly different motor output patterns in an adult STNS monitored by simultaneous extracellular activities from oesophageal $(v p l n)$, pyloric $(P D n)$, and gastric $(G A S T n)$ nerves. $P_{\text {OEso }}$, oesophageal period; $P_{P Y L}$, pyloric period; $P_{G A S T}$, gastric period. Calibration, $1 \mathrm{sec}$.

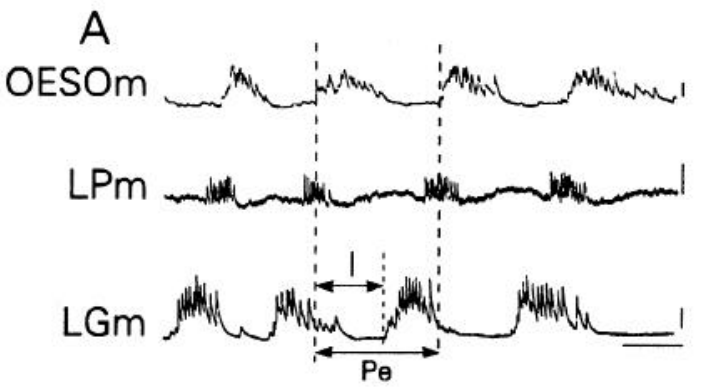

C

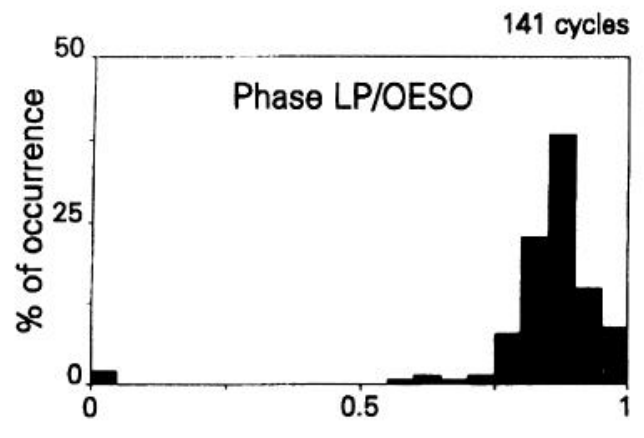

B

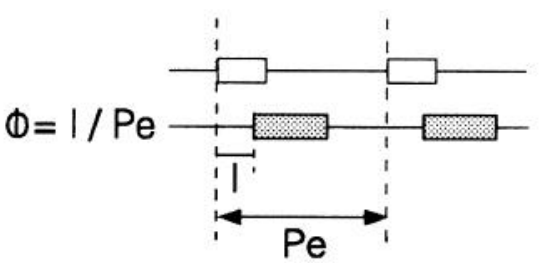

D

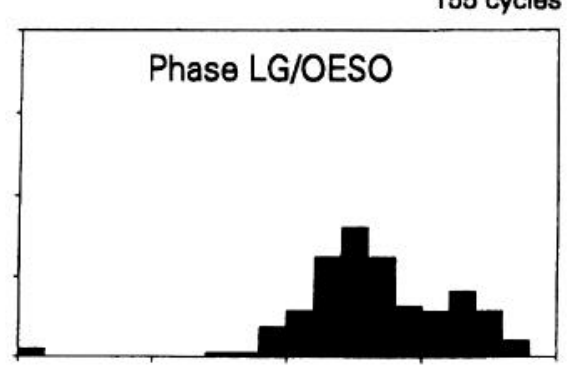

Figure 8. Characterization of the unique embryonic STNS motor pattern. $A$, Spontaneous rhythmic motor output generated by an embryonic STNS in vitro, monitored by simultaneous intracellular recordings from oesophageal $(O E S O m)$, pyloric (lateral pyloric muscle, $L P m$ ), and gastric (lateral gastric muscle, $L G m$ ) stomodeal muscle fibers. $B$, Schematic representation of the different parameters used to calculate the phase. Phase value corresponds to the ratio of latency $(l)$ and the duration of the embryonic cycle period $(P e)$. $C$, Histogram of the phase values of the pyloric muscle $(L P m)$ in the oesophageal muscle cycle $(O E S O m)$. D, Histogram of the phase values of the gastric muscle $(L G m)$ in the oesophageal muscle cycle $($ OESOm) . Calibration: 5 $\mathrm{mV}, 1 \mathrm{sec}$. 


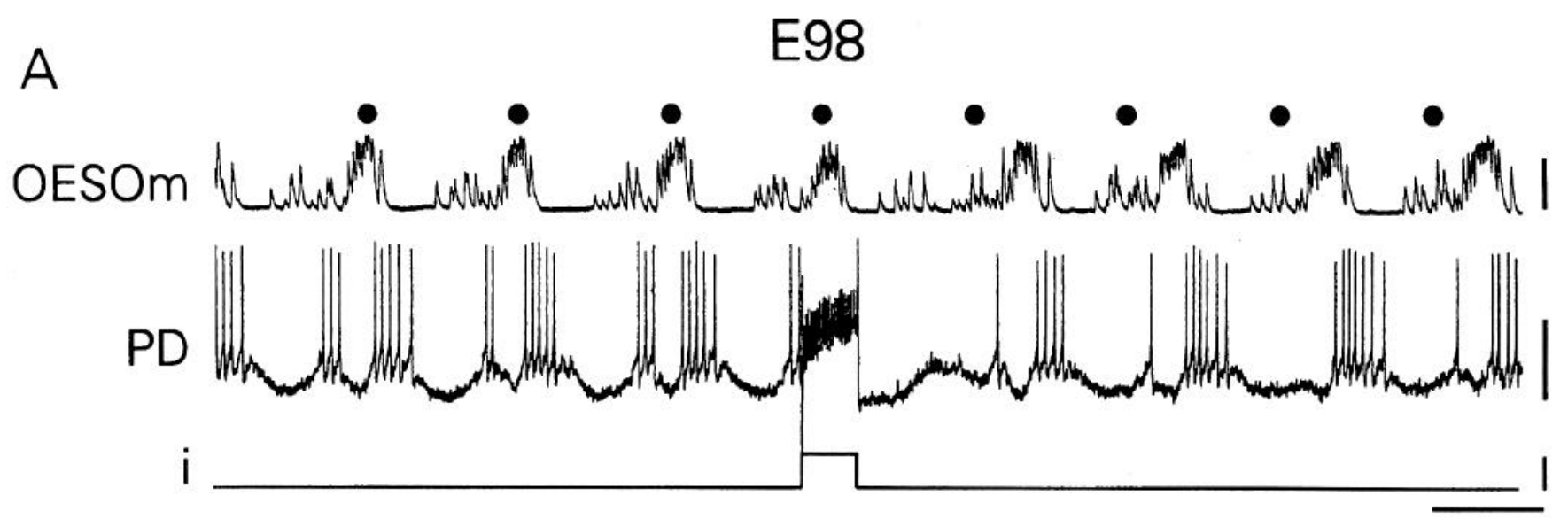

B1
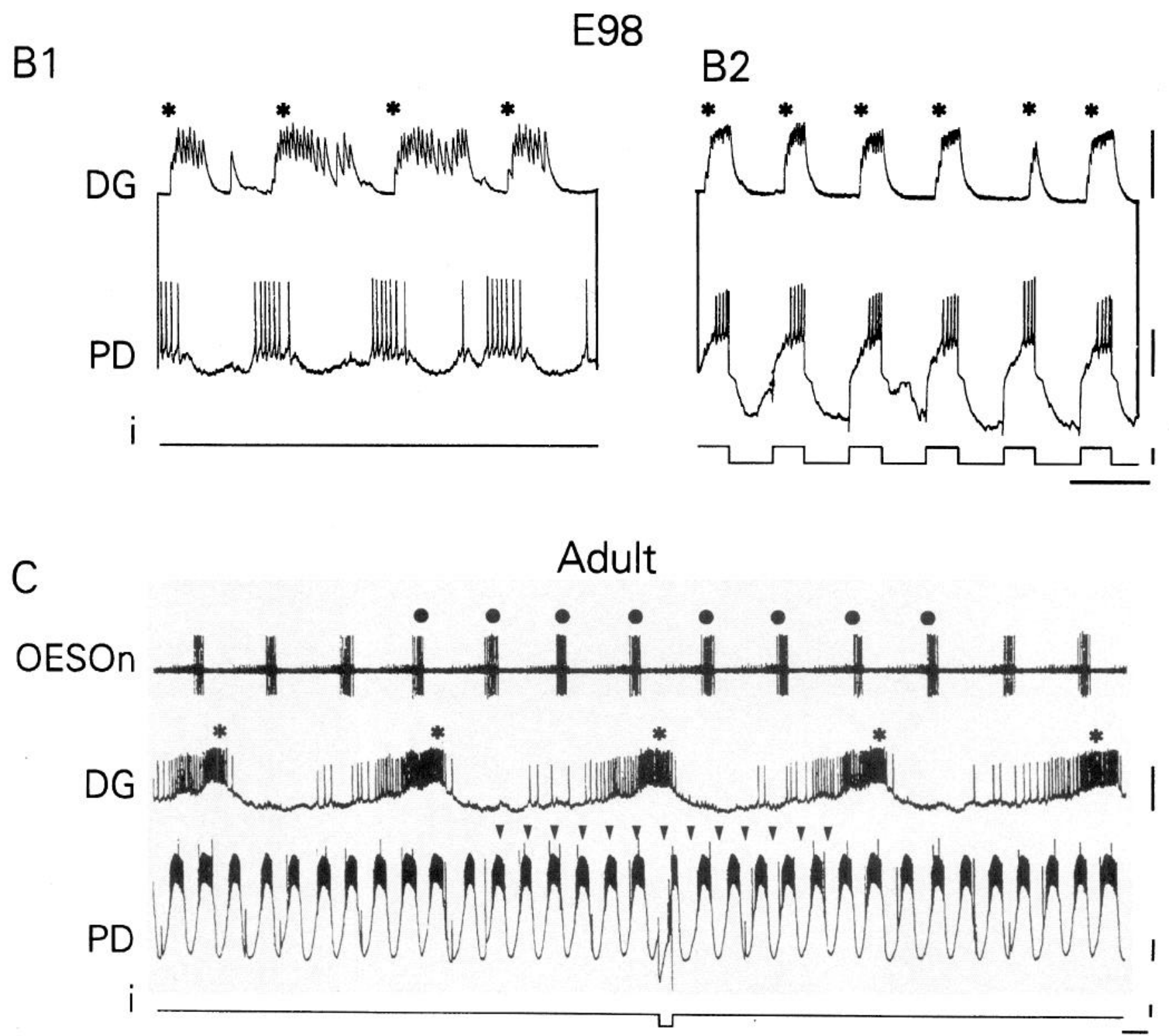

Figure 9. Effects of the discharge of PD neuron on the single embryonic motor pattern $(A, B)$ and the multiple adult networks $(C)$. $A$, A brief discharge of the PD neuron, elicited by direct injection of a depolarizing current $(i)$, resets the ongoing embryonic rhythm which was monitored by an intracellular recording of oesophageal (OESOm) muscle fibers. The dots indicate the expected time of bursting activity in the absence of experimental perturbation. $B$, Repetitive hyperpolarizing current pulses ( $500 \mathrm{msec}$ at $1 \mathrm{~Hz})(i)$ in PD neuron $(B 2)$ caused an increase in its bursting frequency (compare $B 1$ no current injection and $B 2$ ) as well as in the recorded gastric muscle fiber (DGm) used as a monitor of the embryonic motor output. $(C)$ In the adult STNS in vitro, the oesophageal, gastric, and pyloric networks were monitored simultaneously with an extracellular 
bryonic cycles. In the adult Homarus, by contrast, these three foregut regions express independent rhythmic motor activities without any obvious relationship between them (Fig. $7 B$ ).

To analyze the phase relationships between the activity of the different stomodeal muscles (Fig. 8; see also Fig. $10 A, C$ ), phase was calculated as the ratio between the latency (l) of the onset of a subset of pyloric muscle depolarization (here the constrictor muscle LPm) and the embryonic cycle period (Pe) (Fig. 8A,B). To characterize the embryonic period (Pe) we have chosen arbitrarily the constrictor oesophageal muscles activities. At E98, the phase of the pyloric depolarization indicates that the rhythmic oesophageal and pyloric activities are strongly coupled. In fact, pyloric phase values are unimodally distributed and $75 \%$ of the phase values fall within a narrow window between 0.8 and 0.95 (Fig. 8C). Importantly, moreover, this phase distribu-. tion remains the same whatever the stage of embryonic development (E50-60, $n=2$; E60-80, $n=6$; E80-100, $n=16$ ), and despite the morphological modifications of the stomodeum during this period.

A similar kind of coordination occurs between gastric and oesophageal activities (Fig. 8D). Although the gastric phase values are more hroadly distributed than the pyloric ones, the distribution remains unimodal (Fig. $8 D$ ). Moreover, the duration and firing frequency of the gastric bursts was more variable than the pyloric bursts. For instance, during an ongoing embryonic rhythm some gastric bursts were less robust and, in some embryos, they sometimes completely disappeared during individual oesophageal cycles. When this occurred, however, the subsequent gastric burst was generally more intense and of longer duration.

Altogether, the analysis of the phase relationships indicates that the motor activities of the different parts of the stomodeum are linked, indicating that they may be driven by a single neural network within the STNS. If the STG neurons are integral members of a large embryonic neural network instead of simple followers of a rhythmic descending input, then the firing of a STG neuron should be able to alter the ongoing embryonic rhythmic activity as a whole. That this is the case, is shown in Figure 9, $A$ and $B$, where brief intracellular stimulations of a PD neuron during spontaneous rhythmic activity, modified the output of the entire embryonic network. A brief stimulation of this neuron provokes its firing, causing complete resetting of ongoing network activity monitored by the OESOm muscle (Fig. 9A). Moreover, a provoked alteration of the bursting frequency of the PD neuron also dramatically influenced the output of the embryonic network, here monitored by the activity of the DG muscle (Fig. $9 B$ ). When the PD neuron was rhythmically hyperpolarized, its own bursting frequency increased, as well as the DG muscle (compare B1 and B2 in Fig. 9B), again indicating a connection between these elements. Although not all the embryonic STG neurons have the same capability to reset an ongoing rhythmic motor pattern, we found that $61.1 \%$ of the neurons tested are able to provoke an alteration of an ongoing embryonic motor pattern $(n=18)$. In contrast, under the same experimental conditions in the adult STNS, STG neurons are unable to modify the outputs of the other networks to which they do not belong (Fig. 9C). In the adult STNS, a brief provoked hyperpolarization in PD neuron was still able to reset its own network (see arrowheads, Fig. 9C). However, it did not at all alter the ongoing activity of either the gastric (see stars, Fig. $9 C$ ) or the oesophageal (see dots, Fig. 9C) networks monitored by DG neuron and oesophageal motor nerve OESOn, respectively. Altogether, these data strongly suggest that in the embryo, the STNS consists of a single functional network responsible for generating a unique motor pattern.

Since the embryonic motor pattern continues to be expressed throughout the embryonic and prehatching periods, a time when the stomodeum is not functional, it was important to know when this single motor program begins to change into the set of independent motor patterns characteristic of the adult STNS (see Figs. $1 B, 7 B, 9 C, 11 C$ ). Although the stomodeum becomes functional just after hatching (Wells, 1976) and the larval foregut undergoes several morphological changes (Factor, 1981), our recordings from nerve-muscle preparations have shown that the larval foregut still expresses the single embryonic rhythmic motor pattern (Fig. 10A,C) during all three larval stages (i.e., larva I, II, III) (data not shown) and that the first reliable change from this embryonic motor pattern occurs when the animal begins its benthic life at post-larva IV. At this stage, the nesophageal and pyloric rhythms remain coordinated (Fig. 10B) but the gastric rhythm has started to "escape" from the embryonic/larval rhythm (Fig. 10D). Thus, at post-larva IV the oesophageal and pyloric muscles are rhythmically activated with the same cycle frequency, whereas the gastric muscles show rhythmic bursts of EJPs at a separate cycle frequency (Fig. 11B). Because the gastric cycle period is the longest at this stage, we looked at the distribution of the phase of the oesophageal activity during the gastric period and compared it to that of the embryo (Fig. $10 C, D$ ). Additionally, the phase of activity of pyloric units, although still unimodal (Fig. 10B), expressed a wider distribution than during the embryonic period (compare Fig. 10A,B). This indicated that changes also begin to occur in the coordination of these two parts of the foregut between the embryonic and the post-larva IV. The gastric period increases and becomes two or three fold longer than the oesophago-pyloric period $\left[P_{\text {gast. }}=3.31\right.$ $\left.\pm 0.65, P_{\text {oeso/pyl }}=1.57 \pm 0.10(n=51)\right]$.

These data suggest that the different rhythmic motor patterns generated by the adult STNS are segregated progressively from a single embryonic network during the course of the postlarval development, as summarized in Figure 11. In the embryo the different regions of the stomodeum express a single rhythmic motor output (Fig. 11Al). At this stage the mean distribution of the cycle periods for each part of the stomodeum is similar ( $n$ $=17$ ). However, whereas the period distributions of activity in future oesophageal and pyloric regions are strictly unimodal and very similar, the gastric region is already tending toward a bimodal distribution (Fig. 11A2). The second component of this distribution indicates that occasionally a gastric burst can fail during an embryonic cycle. Howcver, the main classes of this second component remain a multiple of the embryonic period, indicating a strong link between these cycle frequencies as expected from the phase diagram of the Figures $8 D$ and $10 C$. In post-larva IV, although the distribution of the periods for the oesophageal and pyloric regions still remain similar, the gastric

electrode from the oesophageal motor nerve (OESOn) and intracellularly from the dorsal gastric $(D G)$ and pyloric dilator $(P D)$ neurons. Whereas a brief hyperpolarizing pulse of current $(i)$ injected in PD resets the ongoing pyloric activity (sce arrowheads), it fails to alter the ongoing gastric (see stars) and oesophageal (see dots) rhythms. Calibration: $10 \mathrm{mV}, 1 \mathrm{sec}, 1.5 \mathrm{nA}$. 


\section{EMBRYO}

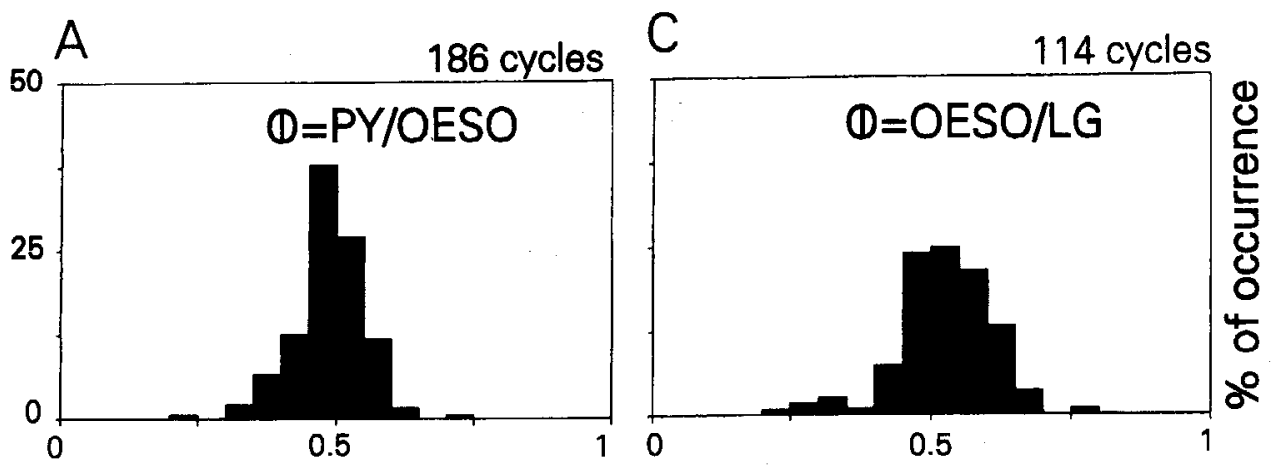

POST-LARVA IV

Figure 10. Evolution of the coordination between the different regions of the foregut during development. $A$ and $B$ show histograms of the phase values of pyloric constrictor muscle activity $(P Y)$ in the oesophageal period of the embryo $(A)$ and the post-larva IV $(B)$. $C$ and $D$ show histograms of the phase values of oesophageal constrictor muscle activity in the gastric $(L G)$ period of the embryo $(C)$ and post-larva IV (D).

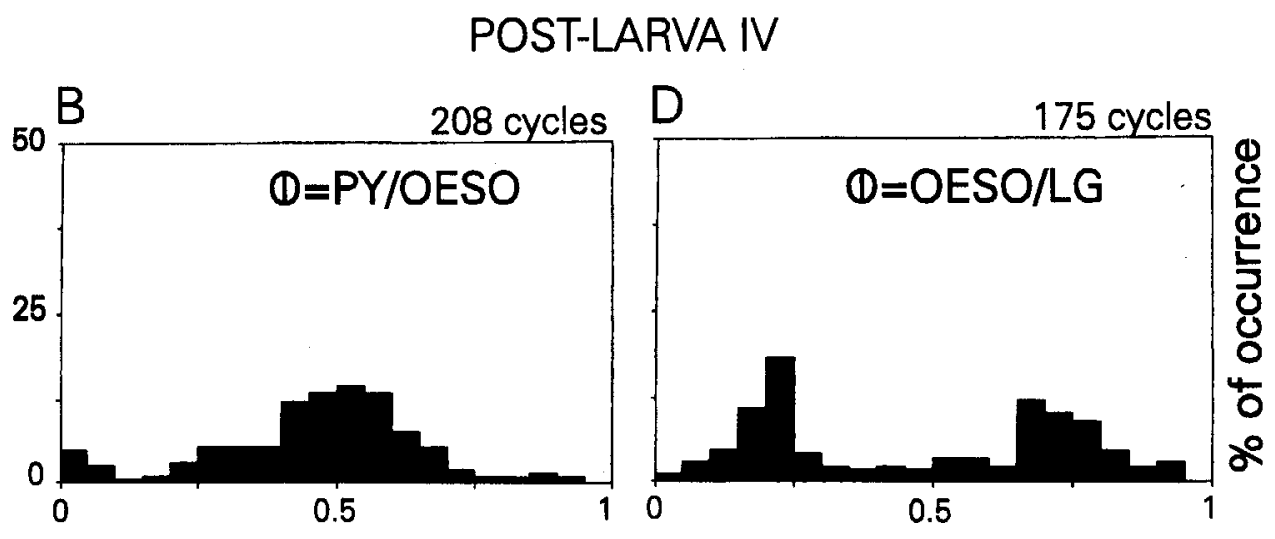

period increases dramatically and the gastric rhythm is no longer strictly coordinated one for one with the late embryonic activity, indicating that the gastric network has differentiated and started to operate at its own intrinsic cycle frequency (Fig. $11 B 1, B 2 ; n$ $=3$ ). Eventually in the adult, the different parts of the foregut express three different and independent rhythms with their own cycle frequencies (Fig. 11C1,C2).

\section{Discussion}

We have shown that in the lobster Homarus gammarus, the stomodeum and the STNS appear early in embryogenesis. Furthermore, the stomodeal muscles are inncrvated by burst-gencrating STNS motoneurons early in development. Most importantly, our results indicate that multiple independent neural networks that are involved in different behavioral tasks in adulthood, emerge from a single embryonic network during the course of development.

\section{Ontogeny of the foregut and STNS}

Although previous developmental studies in lobsters have focused on Homarus americanus (Bumpus, 1891; Herrick, 1895; Factor, 1981; Charmantier, 1987; Charmantier and Aiken, 1987), recent comparative developmental work has shown that $H$. americanus and $H$. gammarus share similar morphological and anatomical features (Gruffydd et al., 1975). In H. gammarus, as in other decapod crustaceans (Bumpus, 1891; Regnault, 1972), the future foregut appears as a depression of the ectoderm followed by its invagination toward the yolk. This folding of the ectoderm to form the stomodeum occurs very early during development and can be observed as early as E5 in $H$ gammarus. Working on H. americanus, Bumpus (1891) noted that the sto- modeum is present from stage "J," the equivalent to E4-5 on the staging scale of Helluy and Beltz (1991). This early development of the foregut is consistent with general crustacean ontogeny, since in many species hatching occurs at the nauplius stage (corresponding to E5 in Homarus), and consequently the stomodeum must be well developed to permit feeding in these free swimming larvae. The late ontogeny of the foregut involves a progressive acquisition of the internalized gastric teeth which are still not present in the gastric mill system even at larval stage I and II. The medial tooth appears tirst at larval stage III, while the lateral teeth first appear at the next post-larva IV (Factor, 1981).

Unlike the progressive changes in the morphological properties of the foregut, we found that the neuronal population within the STG seems to remain constant during the same time in development, with the number of neurons within the STG at E20 being already similar to that of the adult. Although small differences in cell number were seen from one stage to another, these variations are not likely to be developmental in origin, because similar variability has also been observed in the adult STG (Maynard and Dando, 1974; King, 1976). Thus we conclude that the final neuronal population of the STG appears to become established very early during development.

\section{Rhythmic activity of the stomodeum}

Early in development, the entire stomodeum spontaneously expresses a single rhythmic activity that we have confirmed to be neuronally driven from at least E34 (see Fig. 7A). Although rhythmic motion of embryos is a common developmental feature (Hamburger and Oppenheim, 1967; De Vries et al., 1982; Smotherman et al., 1988), in the present case, the rhythmic ac- 


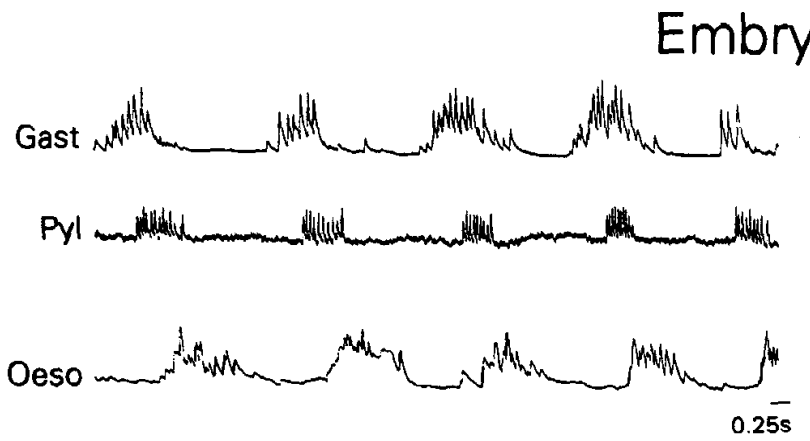

B1

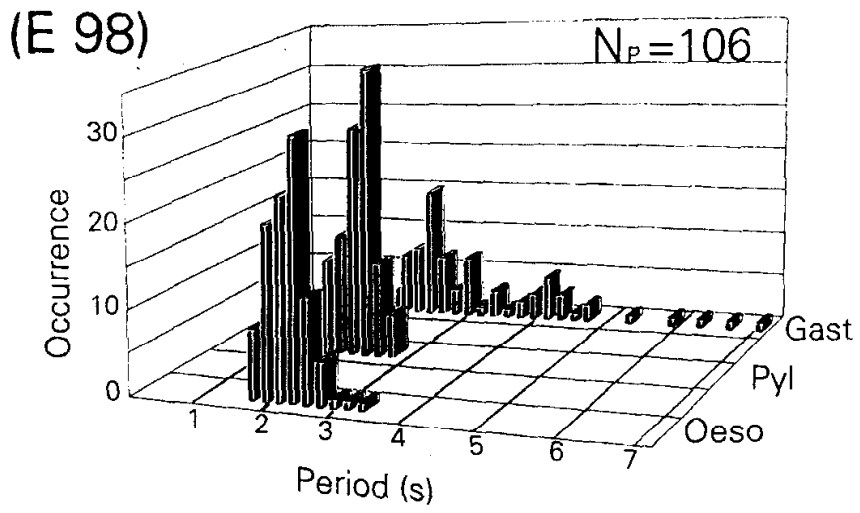

B2

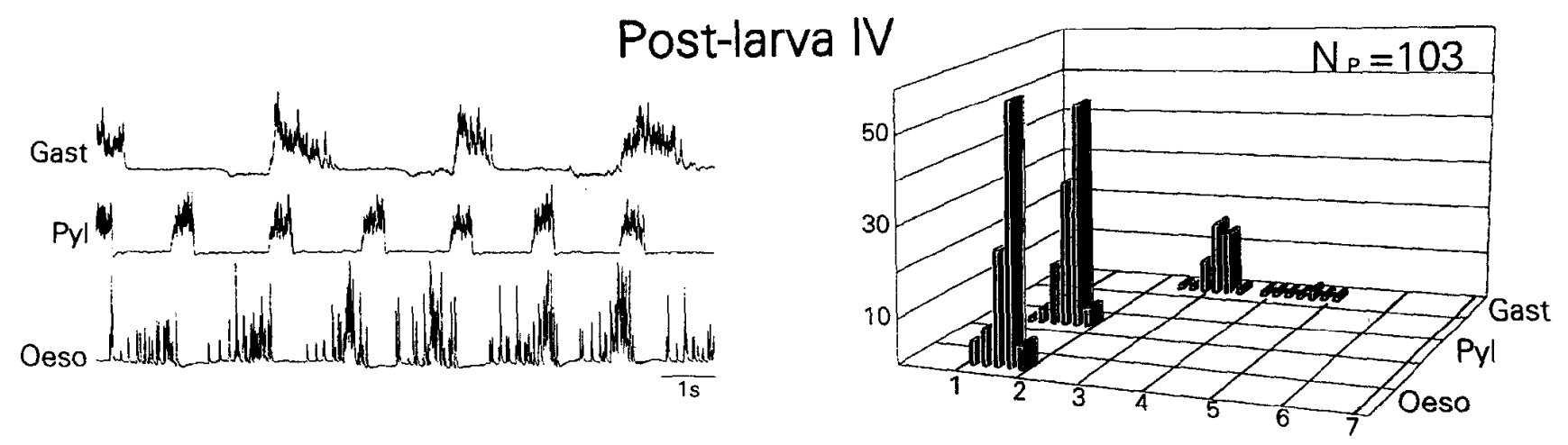

C1
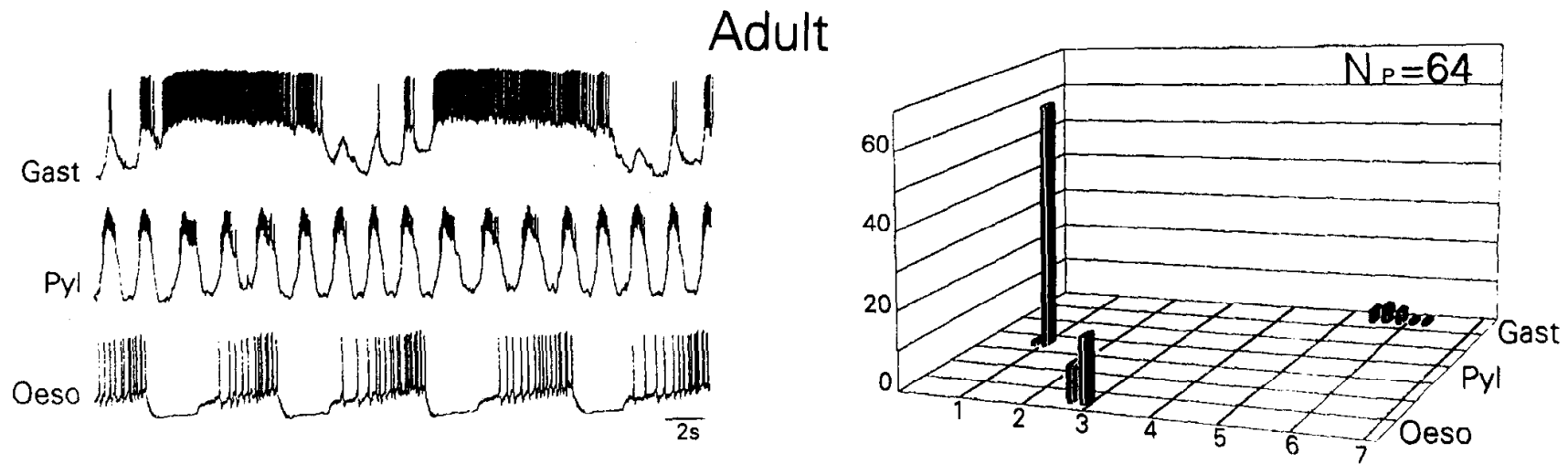

Figure 11. Differentiation of multiple adult motor patterns from a single embryonic network. $A 1, B I$, and $C$, Summary recordings showing the evolution of STNS activity during the course of development. Spontaneous sequences of STNS output were monitored intracellularly from the evolution of STNS activity during the course of $(B I)$, and from their motoneurons for the adult $(C I)$. $A 2, B 2$, and $C 2$, Histograms, constructed for muscles for the embryo $(A I)$, the post-larva IV $(B 1)$, and from their motoneurons for the adult $(C J)$. $A 2$, $B 2$, and $C 2$, Histrion of cycle periods for individual experiments from an embryo at E98 $(A 2)$, a post-larva IV $(B 2)$, and an adult $(C 2)$, represcnting the distribution of cycle periods foch elements participating in the three rhythms. Measurements are made from a sequence
bin corresponds to $0.2 \mathrm{sec}$ interval. Calibration: $A l, 0.25 \mathrm{sec}, B 1,1 \mathrm{sec} ; C 1,2 \mathrm{sec}$. 
tivity of the stomodeum is somewhat surprising because the stomodeum remains nonfunctional until after hatching. Indeed the stomodeum of some embryonic crustaceans is a "blind bag" lacking any connection with other parts of the embryo (Lovett and Felder, 1989). The timing for the functional coupling of the distal part of the stomodeum with the midgut and the hepatopancreas remains unknown (Lovett and Felder, 1989). Although we do not know the precise functional significance of this early spontaneous rhythmicity, several explanations are possible. First, this motor activity is reminiscent of a swallowing-like activity that is characterized by a peristaltic wave that travels from the future mouth until the pyloric region, and typical of foregut activity in primitive crustaceans (Marshall and Orr, 1960) and some decapod larvae (Lovett and Felder, 1990). In Homarus, where hatching occurs relatively late (Helluy et al., 1993), it is . possible that the nonfunctional embryonic stomodeum expresses a fictive swallowing-like activity as a phylogenic consequence rather than for any immediate functional reasons. Second, the lobster embryo passes through as many as seven molts in ovo (Goudeau et al., 1990; Helluy and Beltz, 1991). Since the stomodeum is ectodermal in origin, and therefore sheds its cuticle at each emhryonic molt, the rhythmic movement of the stomodeum could likely play a main role in this process. Third, the continual activity of the stomodeum and especially that of the stomodeal muscles could activate peripheral sensory neurons, which may play an instructive role in the maturation of the CNS, as has been described in other preparations (Meister et al., 1991).

\section{Differentiation from a single embryonic pattern to multiple adult patterns}

In contrast to most other motor systems, motoneurons of the crustacean STNS are integral members of the CPGs themselves. Therefore, recording their activity provides a reliable operational picture of the CPG to which they belong. The adult STNS has been described as four discrete CPGs, each having a specific neuronal population and a specific motor program and function (Selverston and Moulins, 1987; Harris-Warrick et al., 1992a). In contrast, there is no indication of multiple network organization in the early embryo but rather, the activity patterns of embryonic STNS neurons all point to a single functional network. First of all, neurons of the future pyloric, gastric and oesophagus networks express similar rhythmic activity that is tightly coordinated (see Figs. $7 A, 8 A$ ). In the adult these neurons are segregated in neuronal subpopulations expressing completely different activities (Meyrand et al., 1991, 1994) (see Figs. $1 B, 7 B$, $9 C, 11 C l$ ). That these embryonic neurons are integral members of the same single neural network is supported by our finding that at least some embryonic STG cells can alter the ongoing rhythm when experimentally perturbed (Fig. 9A,B). This indicates that the neurons of the STG are not merely passively driven and coordinated by some rhythmic descending inputs from other parts of the STNS. Our results suggests that during subsequent stages in development, this single embryonic network is then progressively divided up into multiple and novel functional networks which characterize the adult STNS (Selverston and Moulins, 1987; Meyrand et al., 1994).

The analysis of the mechanisms underlying these developmental changes in the STNS networks is beyond the scope of this paper. However, it appears that, in Homarus, the maturation of the adult neural networks involves neither the elimination of certain neuronal elements by programmed cell death (Truman, 1983; Oppenheim, 1991) nor the addition of elements by post- embryonic neurogenesis (Thomas et al., 1984), because the final neuronal population in the STG occurs very early and remains stable during the course of subsequent development (Garzino and Reichert, 1994). Growth or regression of some dendritic structures can modify neuronal circuitry during development (Levine and Truman, 1985; Jacobs and Weeks, 1990) and in some adult nervous systems under the influence of steroid hormones (Nottebohm, 1981; Forger and Breedlove, 1987), but such dendritic remodelling has not been examined in the STNS. Developmental alterations in neural network activity may occur at three main levels involving (1) synaptic connections, (2) cellular properties, (3) descending modulatory inputs. In the adult STNS, the strength of some synaptic connections is dynamically altered by neuromodulators, including many peptides and amines, which thereby modify the functional output of the network as a whole (Dickinson and Moulins, 1992; Harris-Warrick et al., 1992b). Such functional rewiring could also play an important role in the developmental emergence of adult STNS networks. For example, neuromodulatory transmitters may not appear or be effective until relatively late in development. In Homarus, the serotonergic (Beltz et al., 1990) and dopaminergic (Cournil et al., 1994) modulatory systems express considerable developmental plasticity which could in turn play a role in determining the functional strengths of specific synaptic connections. Another feature that may influence the development of the STNS networks is changes in the electrophysiological properties of the neurons themselves. One striking feature of embryonic STG neurons is that they seem incapable of the large regenerative depolarizations that are characteristic of the adult STG neurons (compare LP in Figs. 1B, 6A; see Russell and Graubard, 1987, for review). Such differences between the behavior of identified STG neurons in embryo and in adult could be due to two main reasons. First, neuronal membrane properties may themselves undergo developmental changes as has been demonstrated in other systems (McCobb et al., 1990; Hayashi and Levine, 1992; Sillar et al., 1992b). Alternatively or in parallel, developmental changes in the STNS networks might instead derive from the modifications in the descending inputs that control the adult STNS networks. Indeed, it is now clear that virtually all levels of STNS neural networks (synaptic strength, expression of conductances) can be altered by identified neuromodulatory inputs (for review, see Harris-Warrick et al., 1992b).

\section{Comparative aspects of rhythmic motor networks development}

In a wider context, the present results offer new insight into the ontogeny of neural networks responsible for rhythmic behaviors. Stage-specific motor tasks appear and disappear with the changing needs of the developing animal. This raises the question of what happens to the neural networks that generate such transient rhythmic behaviors. In some cases, the neural networks are built and used at the appropriate time. For instance, in insects, certain behaviors involving a sensory-motor loop, such as that involved in larval proleg withdrawal, are lost during the larva-pupal molt (Weeks and Jacobs, 1987; Jacobs and Weeks, 1990), whereas other networks such as the pupal gin-trap network are only acquired during the late development (Levine and Truman, 1983). In the second case, the network corresponding to a specific task is assembled at early stages in development, at a time before the behavior is required. These immature networks are then subject to "developmental tuning" in the interval prior to their functional utilization. For example, in hemimetabolous insects the neural networks for flight are present at preflight stages. Al- 
though flight behavior is expressed only in the adult, it is possible, using specitic stimulation, to trigger components of adult flight in early larval stages (Stevenson and Kutsch, 1988). Moreover, work on many vertebrates systems, such lamprey (Cohen et al., 1990), fish (Batty, 1984), amphibians (Kahn and Roberts, 1982), birds (Bekoff, 1992), and mammals (Robinson and Smotherman, 1992) also indicate that the networks involved in rhythmic motor activities are constructed early in development. Of course, these networks may lack many adult features but within a single neuronal framework, progressive maturation eventually gives rise to an adult circuil configuration. In contrast, we find that in the STNS of Homarus, multiple functional networks differentiate themselves from a single embryonic circuit, whereby its constituent elements seem to be reorganized during ontogeny to create the discrete STNS networks found in the adult.

\section{References}

Batty RS (1984) Development of swimming movements and musculature of larval herring. J Exp Biol 1 10:217-229.

Bekoff A (1992) Neuroethological approaches to the study of motor development in chicks: achievements and challenges. J Neurobiol 23: 1486-1505.

Bekoff A, Lau W (1980) Interlimb coordination in 20-day-old rat fetuses. J Exp Zool 214:173-175.

Beltz BS, Pontes M, Helluy SM, Kravitz EK (1990) Patterns of appearance of serotonin and proctolin immunoreactivities in the developing nervous system of the American lobster. J Neurobiol 21:521542.

Beltz BS, Helluy SM, Ruchhoeft ML, Gammill LS (1992) Aspects of the embryology and neural development of the American lobster. J Exp Zool 261:288-297.

Bumpus HC (1891) The embryology of the American lobster. J Morphol 5:215-262.

Casasnovas B, Cournil I, Meyrand P, Moulins M (1991) Development of neuronal networks in the lobster stomatogastric nervous system. Soc Neurosci Abstr 17:939.

Cazalets JR, Menard I, Crémieux J, Clarac F (1990) Variability as a characteristic of immature motor systems: an electromyographic study of swimming in the newborn rat. Behav Brain Res 40:215225.

Charmantier G (1987) Le développement larvaire et la métamorphose chez les homards (Crustacea, Decapodia). Oceanis 13:137-165.

Charmantier G, Aiken DE (1987) Intermediate larval and postlarval stages of Homarus americanus H. Milne Edwards, 1837 (Crustacea, Decapodia). J Crustacean Biol 7:525-535.

Cohen AH, Dobrov TA, Guan L, Kiemel T, Baker WA (1990) The development of the lamprey pattern generator. J Neurobiol 21:958969.

Cournil I, Helluy SM, Beltz BS (1994) Dopamine in the lobster Homarus gammarus. I. Comparative analysis of dopamine and tyrosine hydroxylase immunoreactivities in the nervous system of the juvenile. J Comp Neurol 334:455-469.

De Vries JIP, Visser GHA, Prechtl HFR (1982) The emergence of fetal behavior. I. Qualitative aspects. Early Hum Dev 7:301-322.

Dickinson PS, Moulins M (1992) Interactions and combinations between different networks in the stomatogastric nervous system. In: Dynamic biological networks: the stomatogastric nervous system (Harris-Warrick RM, Marder E, Selverson AI, Moulins M, eds), pp 139-160. Boston: MIT Press.

Dickinson PS, Mecsas C, Hetling J, Teriio K (1993) The neuropeptide red pigment concentrating hormone affects rhythmic pattern generation at multiple sites. J Neurophysiol 69:1475-1483.

Factor JR (1981) Development and metamorphosis of the digestive system of larval lobsters, Homarus americanus (Decapodia, Nephropidae). J Morphol 169:225-242.

Fentress JC (1992) History of developmental neuroethology: early contributions from ethology. J Neurobiol 23:1355-1369.

Forger NG, Breedlove SM (1987) Seasonal variation in mammalian striated muscle mass and motoneuron morphology. J Neurobiol 18: 155-165.
Garzino V, Reichert H (1994) Early embryonic expression of a $60-\mathrm{kD}$ glycoprotein in the developing nervous system of the lobster. J Comp Neurol 346:572-582.

Getting PA (1989) Emerging principles governing the operation of neural networks. Annu Rev Neurosci 12:185-204.

Goudeau M, Lachaise F, Carpentier G, Goxe B (1990) High titers of ecdysteroids are associated with the secretory process of embryonic envelopes in the european lobster. Tissue Cell 22:269-281.

Grillner S (1985) Neurobiological bases of rhythmic motor acts in vertebrates. Science 228:143-149.

Grillner S, Wallén P, Lansner A, Brodin L (1990) Neuronal network generating locomotor behavior in the lamprey: circuitry, transmitters, membrane properties and simulations. Annu Rev Neurosci 11:169199

Gruffydd LLD, Reiser RA (1975) A comparison of growth and temperature tolerance in the larvae of the lobster Homarus gammarus and Homarus americanus (Decapodia, Nephropidae). Crustaceana 28:23-32.

Hamburger V, Oppenheim R (1967) Prehatching mobility and hatching behavior in the chick. J Exp Zool 166:171-204.

Harris-Warrick RM, Marder E (1991) Modulation of neural networks for behavior. Annu Rev Neurosci 14:39-57.

Harris-Warrick RM, Marder E, Selverson AI, Moulins M, eds (1992a) Dynamic biological networks: the stomatogastric nervous system. Boston: MIT Press.

Harris-Warrick RM, Nagy F, Nusbaum MP (1992b) Neuromodulation of stomatogastric networks by identified neurons and transmitters. In: Dynamic biological network: the stomatogastric nervous system (Harris-Warrick RM, Marder E, Selverston AI, Moulins M, eds), pp 87-138. Boston: MIT Press.

Hayashi JH, Levine RB (1992) Calcium and potassium currents in leg motoneurons during postembryonic development in the hawkmoth Manduca sexta. J Exp Biol 171:15-42.

Helluy SM, Beltz BS (1990) Stages in the embryonic development of the American lobster with special emphasis on its nervous system. In: Frontiers in crustacean neurobiology, pp 523-529.

Helluy SM, Beltz BS (1991) Embryonic development of the American lobster (Homarus americanus): quantitative staging and characterization of an embryonic molt cycle. Biol Bull 180:355-371.

Helluy SM, Sandeman R, Beltz BS, Sandeman D (1993) Comparative brain ontogeny of the crayfish and clawed lobster: implications of direct and larval development. J Comp Neurol 335:343-354.

Herrick FH (1895) The American lobster: a study of its habits and development. Bull US Fish Commun 15:1-252.

Heym C, Forssmann WC (1981) Techniques in neuroanatomical research. Berlin: Springer.

Jacobs GA, Weeks JC (1990) Postsynaptic changes at a sensory-tomotoneuron synapse cause the developmental loss of a reflex behavior during insect metamorphosis. J Neurosci 10:1341-1356.

Kahn JA, Roberts A (1982) The central nervous origin of the swimming motor pattern in embryos of Xenopus laevis. J Exp Biol 99: $185-196$.

King DG (1976) Organization of crustacean neuropil. I. Patterns of synaptic connections in lobster stomatogastric ganglion. J Neurocytol 5:207-237.

Levine RB, Truman JW (1983) Peptide activation of a simple neuronal circuit. Brain Res 279:335-338.

Levine RB, Truman JW (1985) Dendritic reorganization of abdominal motoneurons during metamorphosis of the moth, Manduca sexta. J Neurosci 5:2424-2431.

Lovett DL, Felder DF (1989) Ontogeny of gut morphology in the White shrimp Penaeus setiferus (Decapodia, Penaeidae). J Morphol 201:253-272.

Lovett DL, Felder DF (1990) Ontogeny of kinematics in the gut of the white shrimp Penaeus setiferus (Decapodia, Penaeidae). J Crustacean Biol 10:53-58.

Marshall SM, Orr AP (1960) Metabolism and growth. In: Feeding and nutrition. The physiology of Crustacea, pp 227-258. New York: Academic.

Maynard DM, Darido MR (1974) The structure of the stomatogastric neuromuscular system in Calinectes sapidus, Homarus americanus and Panulirus argus. Philos Trans R Soc Lond [Biol] 268:161-220.

McCobb DP, Best PM, Beam KG (1990) The differentiation of excitability in embryonic chick motoneurons. J Neurosci 10:2974-2984.

Meister M, Wong ROL, Baylor DA, Shaltz CJ (1991) Synchronous 
bursts of action potentials in ganglion cells of the developing mammalian retina. Science. 252:939-943.

Meyrand P, Simmers J, Moulins M (1991) Construction of a pattern generating circuit with neurons belonging to different networks. Nature 351:60-63.

Meyrand P, Simmers J, Moulins M (1994) Dynamic construction of a neural network from multiple pattern generators in the lobster stomatogastric nervous system. J Neurosci 14:630-644.

Moulins M, Vedel J (1977) Programmation centrale de l'activité motrice rhythmique du tube digestif antérieur chez les crustacés décapodes. J Physiol (Paris) 73:471-510.

Nottebohm F (1981) A brain for all seasons: cyclic anatomical changes in song control nuclei of the canary brain. Science 214:1368-1370.

Oppenheim RW (1991) Cell death during development of the nervous system. Annu Rev Neurosci 14:453-501.

Pearson KG (1993) Common principles of motor control in vertebrates and invertebrates. Annu Rev Neurosci 16:265-297.

Peiper A (1963) Cerebral function in infancy and childhood. New York: Consultans Bureau.

Perkins AC (1972) Developmental rates at various temperatures of embryos of the northern lobster (Homarus americanus. Milne-Edwards). Fishery Bull 70:95-99.

Regnault M (1972) Développement de l'estomac chez les larves de Crangon septemspinosa Say (Crustacea, Decapoda. Crangonidae): son influence sur le mode de nutrition. Bull Mus Natl Hist Nat Zool $67: 841-856$

Robinson SR, Smotherman WP (1992) Fundamental motor patterns of the mammalian fetus. J Neurobiol 23:1574-1600.

Russell DF, Graubard K (1987) Cellular and synaptic properties. In: The crustacean stomatogastric system: a model for the study of central nervous system (Selverston AI, Moulins M, eds), pp 79-100. Berlin: Springer.

Selverston Al, Moulins M (1987) The crustacean stomatogastric sys- tem: a model for the study of central nervous system. Berlin: Springer.

Sillar KT, Simmers, AJ, Wedderburn JFS (1992a) The post-embryonic development of cell properties and synaptic drive underlying locomotor rhythm generation in Xenopus larvae. Proc R Soc Lond [Biol] 249:65-70.

Sillar KT, Wedderburn JFS, Simmers AJ (1992b) Modulation of swimming rhythmicity by 5 -hydroxytryptamine during post-embryonic development in Xenopus laevis. Proc R Soc Lond [Biol] 250:107-114.

Smotherman WP, Robinson SR, Robertson SS (1988) Cyclic motor activity in the fetal rat (Rattus norvegicus). J Comp Psychol 102:7882.

Stehouwer DJ, Farel PB (1985) Development of locomotor mechanisms in the frog. J Neurophysiol 53:1453-1466.

Stevenson PA, Kutsch W (1988) Demonstration of functional connectivity of the flight motor system in all stages of the locust. J Comp Physiol A 162:247-259.

Thomas JB, Bastiani MJ, Bate CM, Goodman CS (1984) From grasshopper to Drosophila: a common plan for neuronal development. Nature 310:203-207.

Truman JW (1983) Programmed cell death in the nervous system of an adult insect. J Comp Neurol 216:445-452.

Truman JW (1992) Developmental neuroethology of insect metamorphosis. J Neurobiol 23:1404-1422.

Watson SJ, Bekoff A (1990) A Kinematic analysis of hindlimb mobility in 9- and 10-day-old chick embryos. J Neurobiol 21:651-660.

Weeks JC, Jacobs GA (1987) A reflex behavior mediated by monosynaptic connections between hair afferents and motoneurons in the larval tobacco hornworm, Manduca sexta. J Comp Physiol 160:315329.

Wells P (1976) Effects of Venezuelan crude oil on young stages of the American lobster Homarus americanus. Ph.D. thesis, University of Guelph, Guelph, Ontario. 